\title{
DOCK8 enforces immunological tolerance by promoting IL-2 signaling and immune synapse formation in Tregs
}

Erin Janssen, ${ }^{1}$ Sudha Kumari, ${ }^{2}$ Mira Tohme, ${ }^{1}$ Sumana Ullas, ${ }^{1}$ Victor Barrera, ${ }^{3}$ Jeroen M.J. Tas, ${ }^{4}$ Marcela Castillo-Rama, ${ }^{1}$ Roderick T. Bronson, ${ }^{5}$ Shariq M. Usmani, ${ }^{4}$ Darrell J. Irvine, ${ }^{2}$ Thorsten R. Mempel, ${ }^{4}$ and Raif S. Geha ${ }^{1}$

'Division of Immunology, Boston Children's Hospital, Department of Pediatrics, Harvard Medical School, Boston, Massachusetts, USA. ${ }^{2}$ Department of Bioengineering and Koch Institute of Integrative Cancer Research, Massachusetts Institute of Technology, Cambridge, Massachusetts, USA. ${ }^{3}$ Harvard T.H. Chan School of Public Health, Boston, Massachusetts, USA. ${ }^{4}$ Center for Immunology and Inflammatory Diseases, Massachusetts Ceneral Hospital, Boston, Massachusetts, USA; Department of Medicine, Harvard Medical School, Boston, Massachusetts, USA. ${ }^{5}$ Dana-Farber Cancer Institute, Harvard Medical School, Boston, Massachusetts, USA.

Patients deficient in the guanine nucleotide exchange factor DOCK8 have decreased numbers and impaired in vitro function of Tregs and make autoantibodies, but they seldom develop autoimmunity. We show that, similarly, Dock $8^{-/-}$mice have decreased numbers and impaired in vitro function of Tregs but do not develop autoimmunity. In contrast, mice with selective DOCK8 deficiency in Tregs develop lymphoproliferation, autoantibodies, and gastrointestinal inflammation, despite a normal percentage and in vitro function of Tregs, suggesting that deficient $T$ effector cell function might protect DOCK8-deficient patients from autoimmunity. We demonstrate that DOCK8 associates with STAT5 and is important for IL-2-driven STAT5 phosphorylation in Tregs. DOCK8 localizes within the lamellar actin ring of the Treg immune synapse (IS). Dock8 ${ }^{-/-}$Tregs have abnormal TCR-driven actin dynamics, decreased adhesiveness, an altered gene expression profile, an unstable IS with decreased recruitment of signaling molecules, and impaired transendocytosis of the costimulatory molecule CD86. These data suggest that DOCK8 enforces immunological tolerance by promoting IL-2 signaling, TCR-driven actin dynamics, and the IS in Tregs.

Conflict of interest: The authors have declared that no conflict of interest exists.

Submitted: March 29, 2017 Accepted: August 29, 2017 Published: October 5, 2017

\section{Reference information:} JCI Insight. 2017;2(19):e94298. https://doi.org/10.1172/jci. insight.94298.

\section{Introduction}

T cells play a critical role in fighting pathogens by generating a diverse repertoire of antigen receptors (1). This diversity leads to the generation of $\mathrm{T}$ cell clones that recognize self-antigen, potentially causing autoimmunity (2). The majority of autoreactive T cell clones are eliminated in the thymus by negative selection. Autoreactive $\mathrm{T}$ cells that escape to the periphery are inactivated by Tregs to maintain peripheral tolerance (3). Interactions between Tregs and DCs are crucial in preventing activation of autoreactive T cells in the periphery (4).

The development of Tregs in the thymus requires intermediate strength interactions between TCRs and self-peptide/MHC ligands and costimulatory signals delivered by CD28 and members of the tumor necrosis factor receptor superfamily $(5,6)$. These signals lead to the upregulation of the high-affinity IL-2 receptor (IL-2R) $\alpha$ chain (CD25). IL-2 signaling via the high-affinity IL-2R complex containing CD25 activates the transcription factor STAT5, which binds to the promoter of the Foxp3 gene. FOXP3 expression is critical for the survival, maintenance, and function of Tregs (7-9). TCR signaling is also important for the induction of Foxp3 gene transcription and Treg function (10). FOXP3 is dispensable for Treg development but is crucial for Treg function, as evidenced by the development of severe autoimmunity in patients and mice deficient in FOXP3 (11). Thus, both IL-2 signaling and TCR signaling are important for Treg function.

Dedicator of cytokinesis 8 (DOCK8) is a member of the DOCK180 superfamily of DOCK proteins with characteristic DOCK homology region 1 (DHR1) and DHR2 domains (12). The DHR1 domain targets DOCK8 to membranes, through binding phosphatidylinositol $(3,4,5)$-triphosphate, while the DHR2 domain binds to, and functions as, a guanine nucleotide exchange factor (GEF) for CDC42 $(13,14)$. The 
GEF activity of DOCK8 is critical for its function (15). DOCK8 regulates actin cytoskeleton-dependent functions in T cells, B cells, NK cells, and DCs (14-18). DOCK8 deficiency in humans is caused by biallelic mutations in DOCK8 that abolish protein expression (19). DOCK8 deficiency is associated with atopic dermatitis, asthma, food allergies, an unusual susceptibility to viral mucocutaneous infections, $\mathrm{T}$ cell lymphopenia, reduced proliferative $\mathrm{T}$ cell responses, decreased cytokine production, and impaired antibody responses $(20,21)$.

We previously reported that the number and in vitro-suppressive function of circulating Tregs are significantly reduced in DOCK8-deficient patients (22). However, DOCK8-deficient patients only sporadically develop autoimmune disease $(20,23-26)$. We report that mice with selective deficiency of DOCK8 in Tregs, but not Dock $^{-1-}$ mice, develop rampant autoimmunity, suggesting that deficient $\mathrm{T}$ effector cells (Teff) function may protect DOCK8-deficient patients from autoimmunity. We show that DOCK8 regulates IL-2-driven STAT5 phosphorylation, TCR-driven actin dynamics, immune synapse (IS) integrity, and transendocytosis in Tregs, all of which are important for maintaining peripheral tolerance.

\section{Results}

DOCK8-deficient mice have decreased numbers and impaired in vitro function of Tregs but do not develop autoimmunity. DOCK8-deficient patients uniformly suffer from infections and skin inflammation and are on multiple medications, which could potentially affect their Tregs (27). To circumvent these limitations, we examined mice that carry a homozygous knockin c.C1074T mutation, recapitulating a mutation in a DOCK $8^{\text {nul }}$ patient (21). These mice, designated Dock8 ${ }^{-1}$ mice, express no detectable DOCK8 protein (16). As previously reported $(15,28)$, the percentage and number of $\mathrm{CD}^{+} \mathrm{T}$ cells and marginal zone $\mathrm{B}$ cells in the spleens of Dock $^{-1-}$ mice were decreased compared with WT controls (Supplemental Figure 1, A and B; supplemental material available online with this article; https://doi.org/10.1172/jci.insight.94298DS1). Proliferation and IL-2 production and secretion by $\mathrm{CD} 4^{+} \mathrm{CD} 25^{-}$Teffs following stimulation with anti-CD3-coated and anti-CD28-coated (anti-CD3+anti-CD28-coated) beads were significantly lower in Dock8 ${ }^{-1-}$ mice compared with WT littermates (Figure 1, A and B, and Supplemental Figure 1C).

The percentage of $\mathrm{CD}^{+} \mathrm{CD} 25^{+} \mathrm{FOXP}^{+}$Tregs among $\mathrm{CD} 4^{+} \mathrm{T}$ cells in the thymus and spleen, but not lymph nodes (LNs), was modestly but significantly decreased in Dock8 ${ }^{-1-}$ mice compared with WT littermates (Figure 1C). There were no significant differences in the percentages of CD44-CD62 $\mathrm{L}^{\text {hi }}$ resting Tregs (rTregs) and $\mathrm{CD} 44^{+} \mathrm{CD} 62 \mathrm{~L}^{\text {lo }}$ activated cells (aTregs) (29) in the spleens and LNs of Dock8 ${ }^{-1}$ mice (Figure 1D and data not shown). Expression of CD25, but not FOXP3, CTLA-4, HELIOS, ICOS, or CD39, was significantly lower in Tregs from Dock8 ${ }^{-1-}$ mice compared with WT controls (Figure 1E and Supplemental Figure 1D). Foxp3 and Il2ra mRNA levels were significantly lower in Tregs from Dock $8^{-1-}$ mice compared with WT littermates (Figure 1F). The dissociation between Foxp3 mRNA and FOXP3 protein levels in Dock8 ${ }^{-1}$ Tregs suggests that posttranslational control of FOXP3 protein expression (30) and/or the half-life of FOXP3 protein dampens the effect of the molecular differences between Dock8 ${ }^{-1-}$ Tregs and WT Tregs (31-33).

The ability of $\mathrm{CD}^{+} \mathrm{CD} 25^{+} \mathrm{CD} 39^{+}$Tregs from Dock8 ${ }^{-1-}$ mice to suppress the proliferation of WT CD4 ${ }^{+} \mathrm{CD} 25^{-}$Teffs in response to soluble anti-CD3 and antigen-presenting cells (APCs) was significantly decreased compared with that of Tregs from WT controls (Figure 1G). Tregs suppress the proliferation of Teffs by several mechanisms, including competition for IL-2 (34) and production of the inhibitory cytokines TGF- $\beta$ and IL-10 $(35,36)$. In addition to decreased CD25 surface expression, which reduces the ability to compete for IL-2, sorted CD ${ }^{+} \mathrm{CD} 25^{+} \mathrm{CD} 39^{+}$Tregs from Dock8 ${ }^{-/}$mice had significantly impaired $\mathrm{Tg} f$, but not Il10, expression compared with WT controls (Figure 1H). When Tregs from Dock $8^{-1-}$ and WT mice were preactivated with IL-2 and anti-CD3+CD28 beads, there was no significant difference in their ability to suppress Teff proliferation (Supplemental Figure 1E). This supports a role for decreased IL-2 secretion from Dock $8^{-1-}$ Teffs in impairing the in vitro-suppressive ability of Tregs from Dock $8^{-1-}$ mice.

Despite the decreased percentages and impaired in vitro-suppressive activity of their Tregs, Dock $8^{-1-}$ mice aged for 12 months had normal weight gain and did not develop lymphadenopathy, splenomegaly, anemia, thrombocytopenia, or gastrointestinal inflammation. In addition, their sera did not exhibit increased reactivity to HEp-2 cell antigens or to the 128 autoantigens included in the University of Texas Southwestern panel (37) compared with WT controls (data not shown). Intraperitoneal administration of the TLR3 agonist poly(I:C) for 3 months to mimic microbial stimulation did not elicit autoantibody formation against HEp-2 cells and did not provoke autoimmune disease in Dock $8^{-1-}$ mice (data not shown). 
A
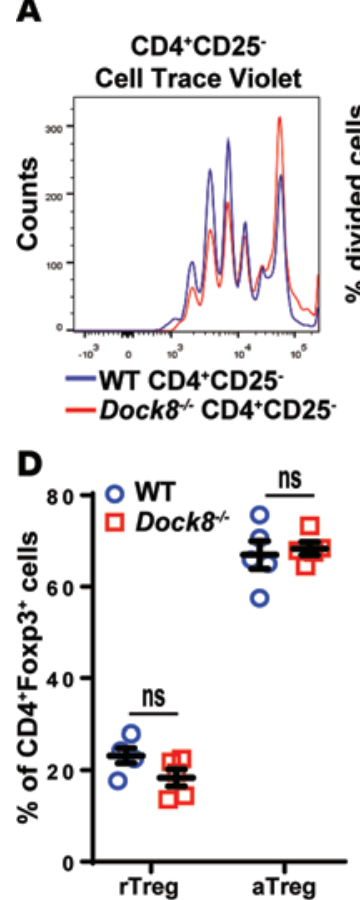

G

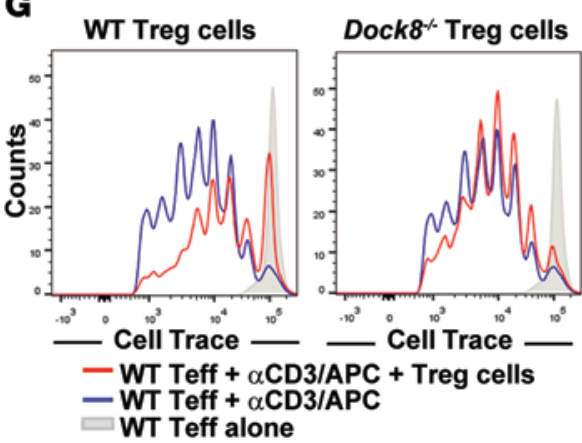

B

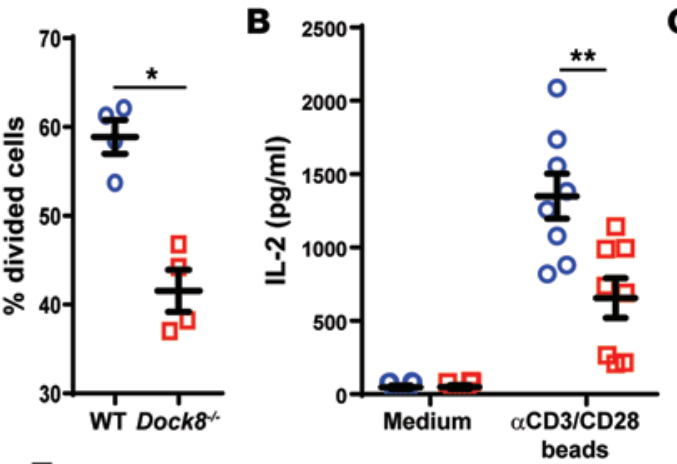

E
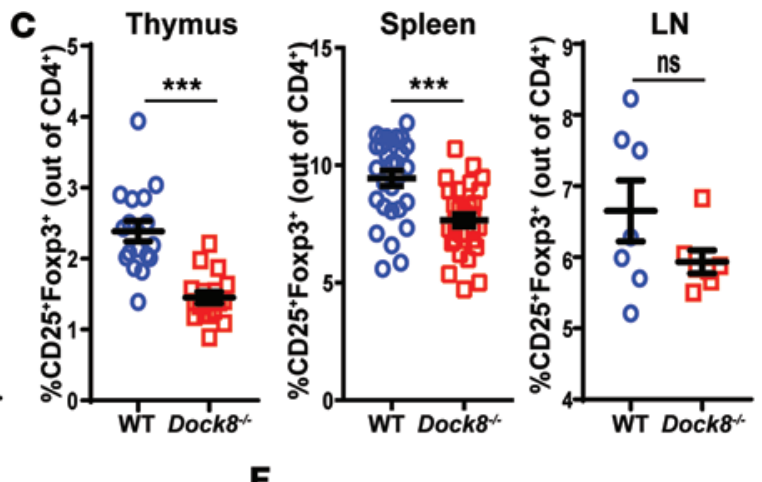

$\mathbf{F}$
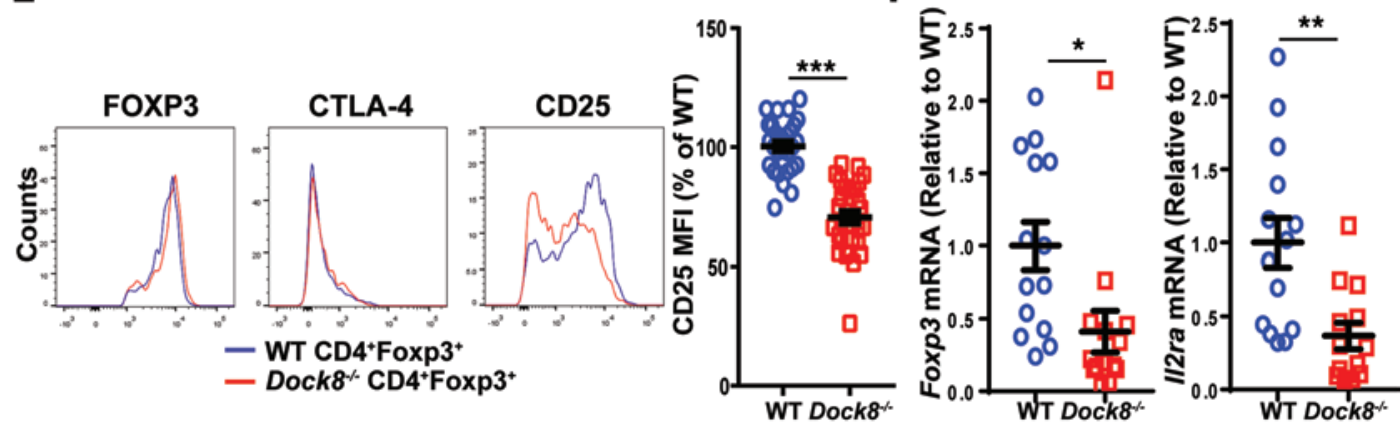

Figure 1. Dock8 -/- $^{-1}$ mice have reduced Treg percentages and in vitro Treg-suppressive ability. (A and B) Proliferation measured by Cell Trace Violet dilution (A) and IL-2 secretion in culture supernatants (B) by CD4+CD25- Teffs isolated from the spleens of Dock $8^{-1-}$ and WT mice cultured for 3 days with anti-CD3+anti-CD28-coated beads. (C) Percentage of CD25 ${ }^{+} \mathrm{FOXP3}^{+}$Tregs among CD4+ cells in the thymuses, spleens, and LNs of Dock $8^{-/-}$and WT mice. $n=17$ mice from each group for the thymus, $n=31$ mice from each group for the spleen, $n=7$ mice from each group for the $L N$. (D) Percentages of CD44-CD62 ${ }^{\text {hi }}$ rTregs and CD44+CD62 ${ }^{10}$ aTregs of total CD4+FOXP3 ${ }^{+}$cells in the spleens of Dock8 ${ }^{-/-}$and WT mice. $n=5$ mice from each group. (E) Representative FACS plots of intracellular FOXP3 and CTLA-4 and surface CD25 expression gating on CD4+FOXP3+ splenocytes (left). Quantitative analysis of surface CD25 expression by splenic CD4 ${ }^{+} \mathrm{FOXP3}^{+}$cells from Dock $8^{--}$mice and WT controls. $n=29$ mice from each group. (F) qPCR analysis of Foxp3 and II2ra mRNA levels in FACS-sorted CD4+CD25+CD39+ Tregs from Dock8 ${ }^{-/-}$and WT mice. Results are expressed as fold increase relative to the WT control ratio of the mRNA of interest/b2microglobulin. (G) Suppression of the proliferation of CD4+CD25- Teffs by CD4+CD25+CD39+ Tregs from Dock $8^{-1}$ mice and WT controls. Teff proliferation was measured by FACS analysis of Cell Trace Violet dilution. The left panel is a representative experiment; the right panel shows the pooled results. (H) qPCR analysis of Tgfb and $/ 110$ mRNA expression by sorted CD4 ${ }^{+} \mathrm{CD} 25^{+} \mathrm{CD} 39^{+}$Tregs from Dock $8^{-/-}$mice and WT controls. Symbols represent individual mice, and error bars represent mean and SEM. Results in $\mathbf{A}$, $\mathbf{B}$, and $\mathbf{F}-\mathbf{H}$ are representative of 3 independent experiments. $t$ test, NS $P>0.05,{ }^{*} P<0.05,{ }^{* *} P<0.01,{ }^{* * *} P<0.001$.

Mice with selective DOCK8 deficiency in Tregs have impaired weight gain and develop lymphoproliferation, systemic inflammation, and anemia. Defective Teff function may have protected Dock $8^{-1-}$ mice from developing autoantibodies and autoimmunity. To test this hypothesis, we examined mice with a selective DOCK8 deficiency

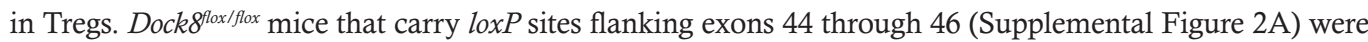
generated and bred with Foxp $3^{Y F P-C r e}$ mice that selectively express a YFP-Cre fusion protein under the control

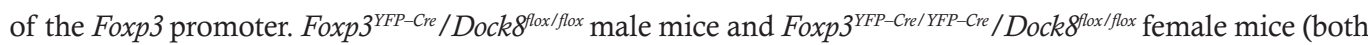

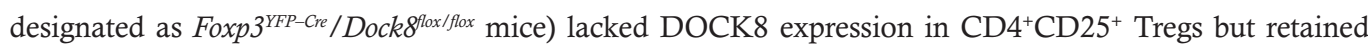
normal DOCK8 expression in $\mathrm{CD} 4^{+} \mathrm{CD} 25^{-}$Teffs (Supplemental Figure 2B). 

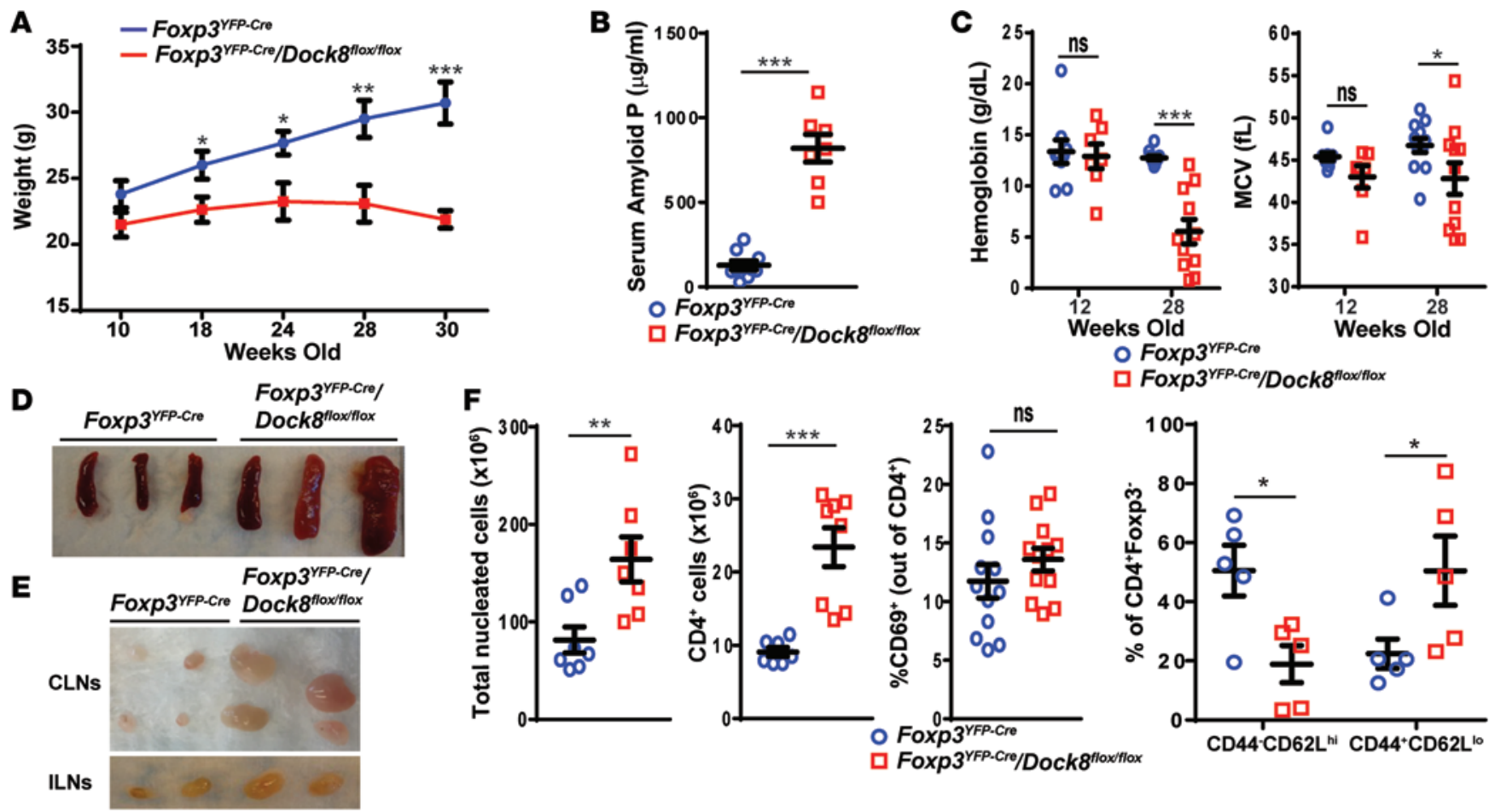

G

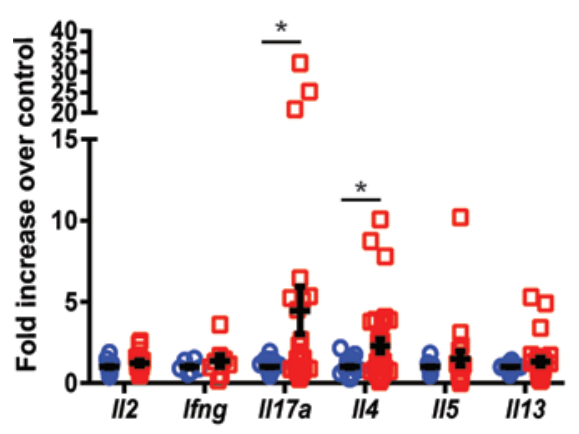

H

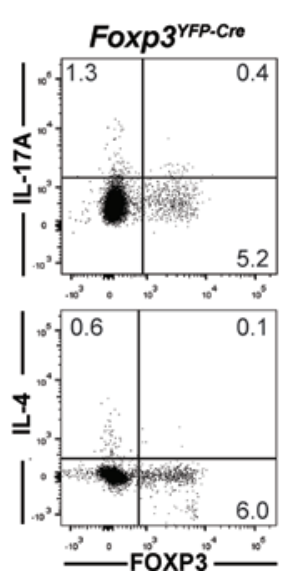

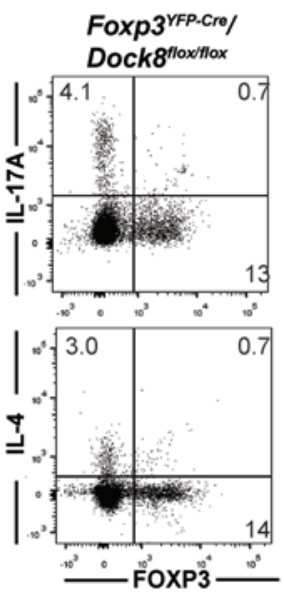

I

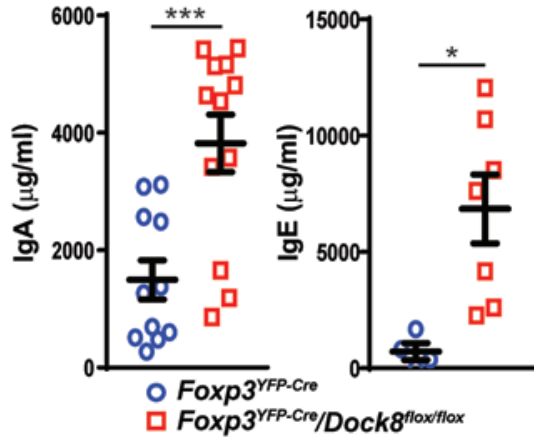

Figure 2. Mice with Treg-specific DOCK8 deficiency develop weight loss, splenomegaly, and lymphadenopathy. (A) Weights between age 10 and 30 weeks

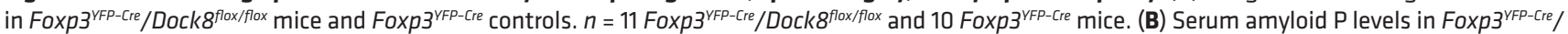
Dock8 flox/flox mice and Foxp3 $3^{Y F P-C r e}$ controls at 28 weeks of age. (C) Hemoglobin concentration and mean red blood cell volume (MCV) in Foxp $3^{\text {YFP-Cre }} / D o c k 8^{f l o x}$ /flox mice and Foxp $3^{\text {YFP-Cre }}$ controls at 12 and 28 weeks of age. (D and E) Representative photographs of the spleens (D), cervical LNs (CLN), and inguinal LNs (ILN) (E) from 30-week-old Foxp3 $3^{\text {YFP-Cre }} /$ Dock8 flox/flox mice and Foxp3 ${ }^{\text {YFP-Cre }}$ controls. (F) Nucleated cells counts, CD4+ cell counts, percentage of CD69+ ${ }^{+}$cells among

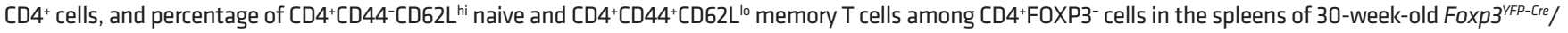

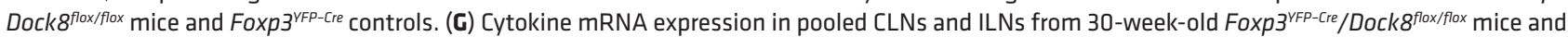

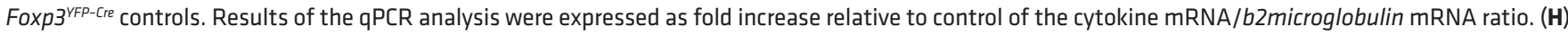
Representative FACS plots showing intracellular cytokine expression after gating on CD4 ${ }^{+}$T cells stimulated for 3.5 hours with phorbol 12,13-dibutyrate and ionomycin. (I) Serum IgA and IgE levels in 28-week-old Foxp $3^{\text {YFP-Cre }} / D o c k 8^{\text {flox/flox }}$ mice and Foxp $3^{\text {YFP-Cre }}$ controls. Symbols represent individual mice, and error bars in A-C, F, G, and I represent mean and SEM. $t$ test, NS $P>0.05,{ }^{*} P<0.05,{ }^{* *} P<0.01,{ }^{* * *} P<0.001$.

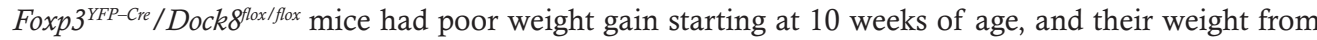
18 weeks of age onward was significantly lower than that of age-matched Foxp $3^{\text {YFP-Cre }}$ controls (Figure 2A). By 28 weeks of age, serum levels of amyloid $\mathrm{P}$, an acute-phase reactant indicative of systemic inflamma-

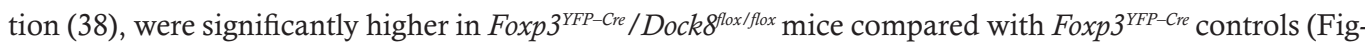
ure 2B). Foxp $3^{\text {YFP-Cre }} /$ Dock $8^{\text {flox/flox }}$ mice developed microcytic anemia with significantly lower hemoglobin concentration and red blood cell volume compared with Foxp $3^{\text {YFP-Cre }}$ controls (Figure 2C). Platelet counts

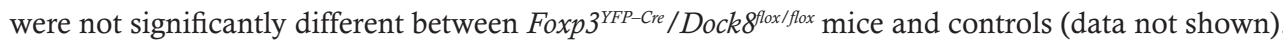


A

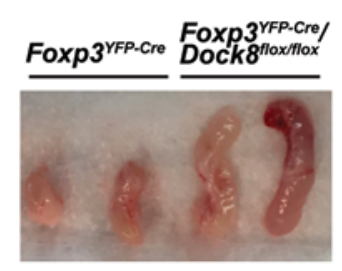

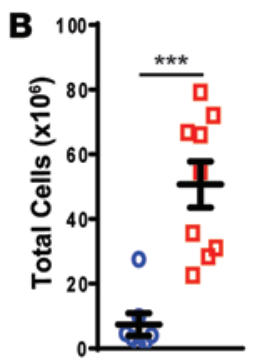

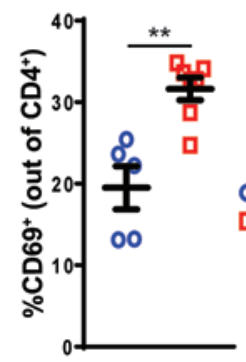

C

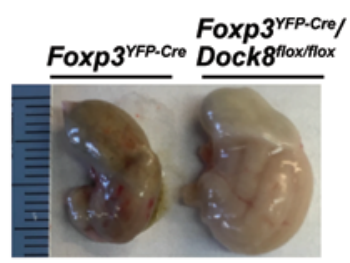

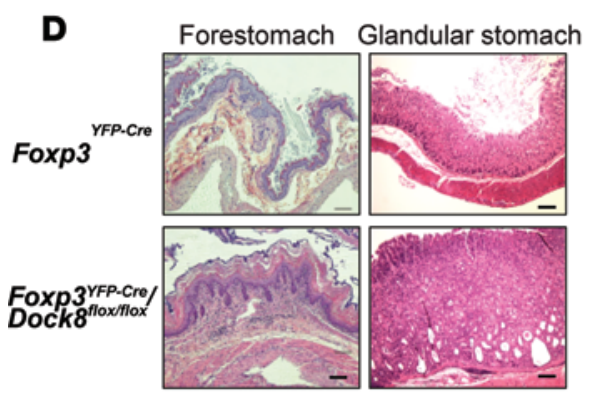

H

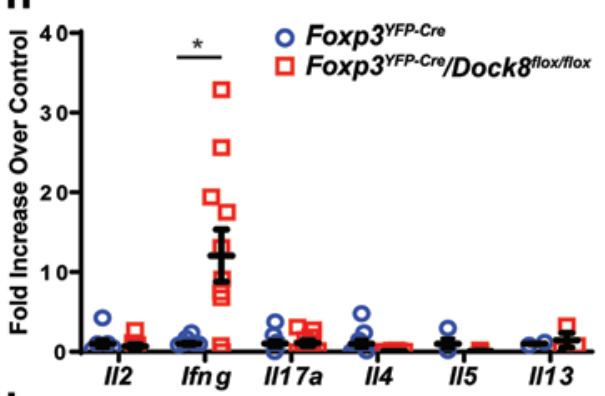

L

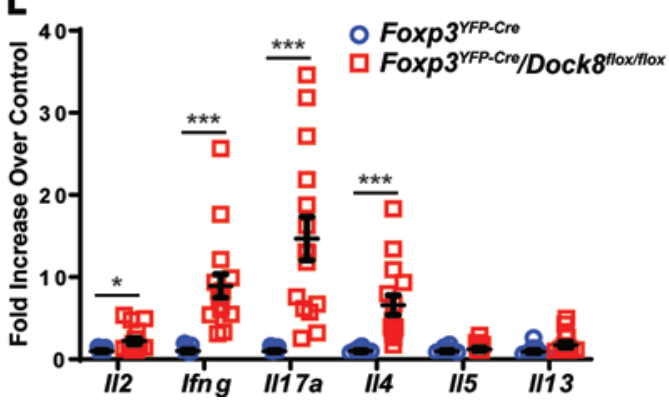

E

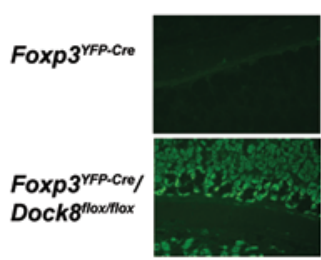

Dilution - 1:80

I
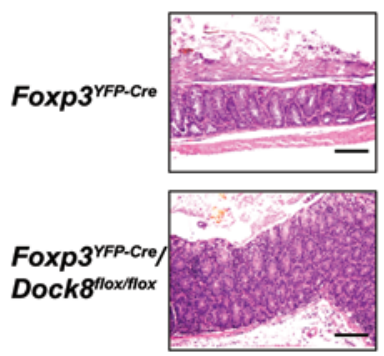

$\mathbf{F}$

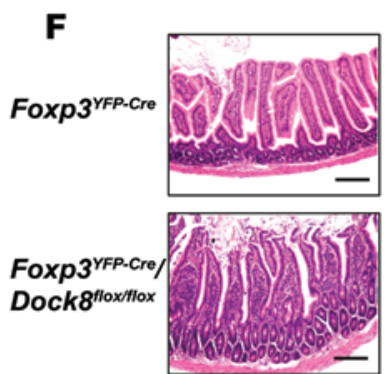

J

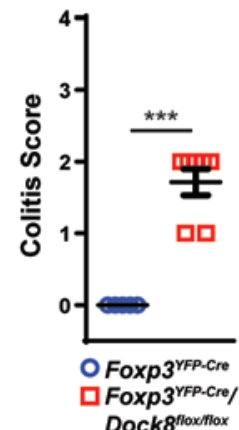

OFoxp3 $3_{\text {YFP.Cre }}$

G $\square$ Foxp $3^{\text {YFP.Cro/ }}$

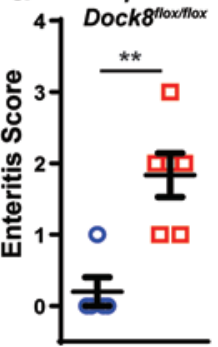

$\mathbf{K}$

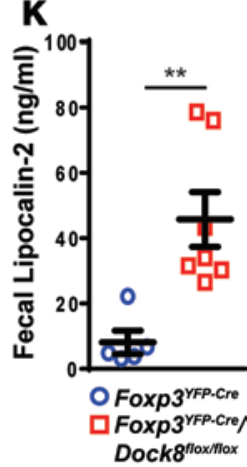

Figure 3. Mice with a Treg-specific DOCK8 deficiency develop gastrointestinal inflammation. (A) Representative photographs of the MLNs from 30-week-old

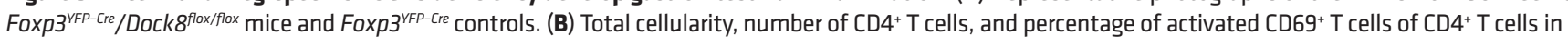

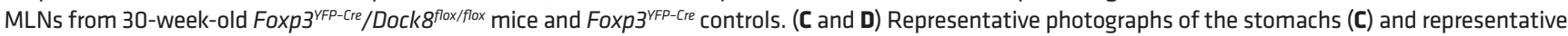
H\&E-stained sections of the forestomach and glandular stomach (original magnification, $\times 10$ ) (D) from 30-week-old Foxp $3^{\text {YFP-Cre }} / D_{\text {Dock }} 8^{\text {flox }}$ fflox mice and Foxp $3^{\text {YFP-Cre }}$ controls. Scale bar: $100 \mu \mathrm{m}$ (D). (E) Representative images (original magnification, $\times 20$ ) of indirect immunofluorescent staining of stomach sections for lgG using dilutions of serum from a 28-week-old Foxp $3^{Y F P-C r e} /$ Dock $8^{\text {floxfflox }}$ mouse and Foxp $3^{\text {YFP-Cre }}$ controls. (F and G) Representative H\&E-stained sections (original magni-

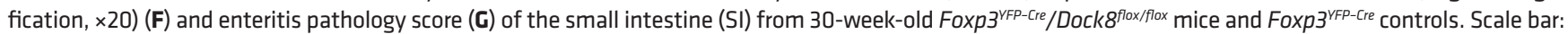

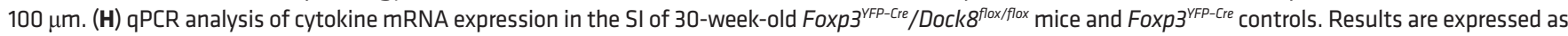
fold increase of the cytokine mRNA/b2microglobulin mRNA ratio relative to control. (I and J) Representative H\&E-stained sections (original magnification, $\times 20$ ) (I) and colitis pathology score (J) of the mid colon from 30-week-old Foxp $3^{Y F P-C r e} / D o c k 8^{\text {flox }}$ flox mice and Foxp $3^{\text {YFP-Cre }}$ controls. (K) Fecal lipocalin-2 concentrations in the stools of 30-week-old Foxp3 $3^{\text {YF-Cre }} /$ Dock $8^{\text {flox/flox }}$ mice and Foxp3 $3^{\text {YFP-Cre }}$ controls. (L) qPCR analysis of cytokine mRNA expression in the colons from 30-week-

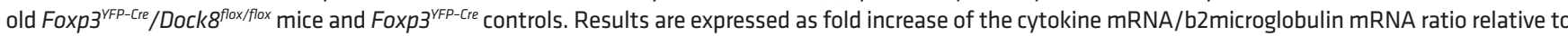
control. Symbols represent individual mice, and error bars in $\mathbf{B}, \mathbf{G}, \mathbf{H}, \mathbf{J}$, and $\mathbf{K}$ represent mean and SEM. $t$ test, ${ }^{*} P<0.05,{ }^{* *} P<0.01,{ }^{* * *} P<0.001$.

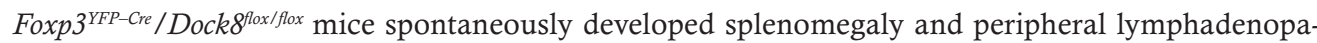
thy by 6-8 weeks of age (Figure $2, \mathrm{D}$ and $\mathrm{E}$ ). Total cellularity and numbers of $\mathrm{CD} 4^{+} \mathrm{T}$ cells, $\mathrm{CD} 8^{+} \mathrm{T}$ cells, and $\mathrm{B} 220^{+} \mathrm{B}$ cells were significantly higher in the spleens and peripheral LNs of Foxp $3^{Y F P-C r e} /$ Dock $8^{\text {flox } / f l o x}$ mice compared with age-matched Foxp $3^{Y F P-C r e}$ controls (Figure 2F; Supplemental Figure 2, C and D; and 
A

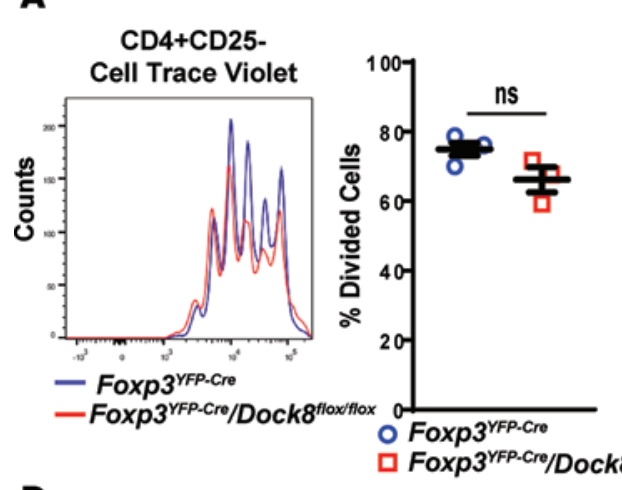

D

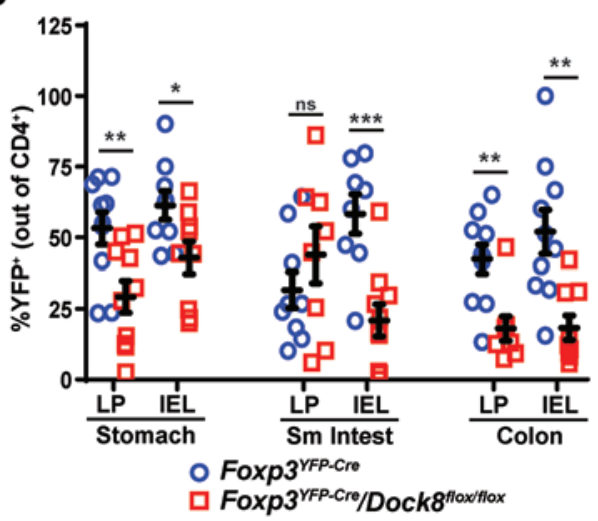

$\mathbf{F}$

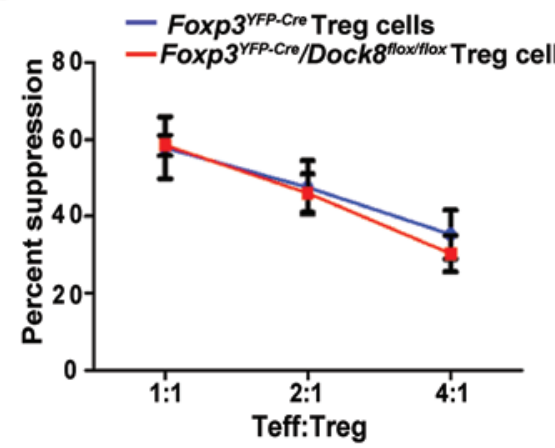

B

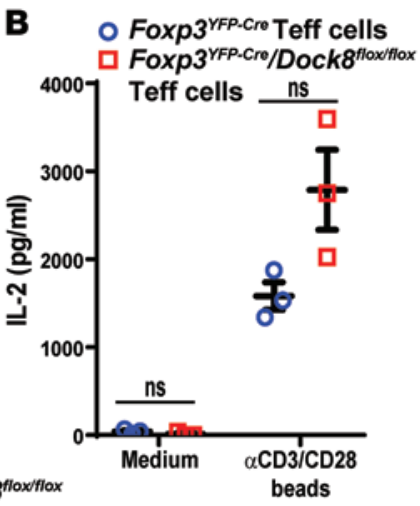

C
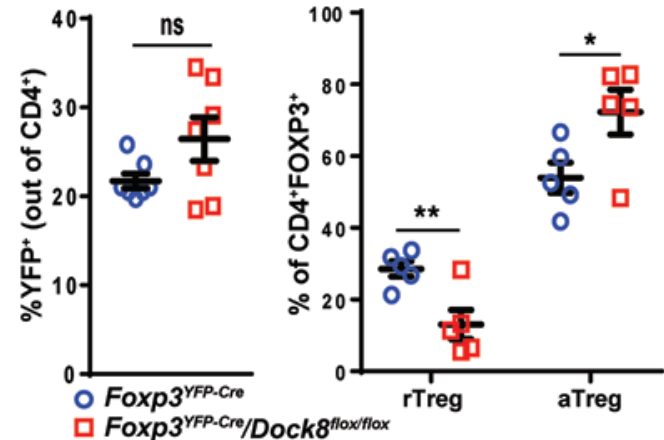

E
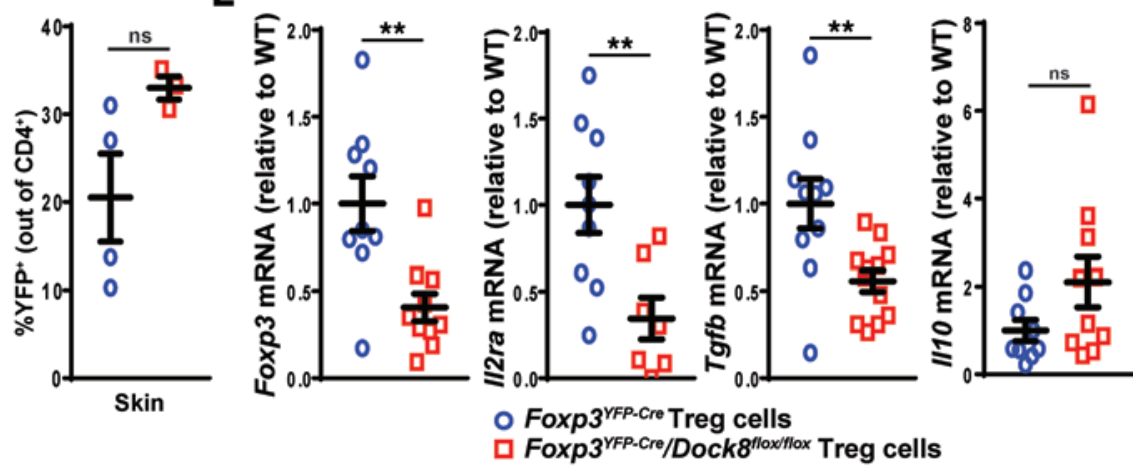

G

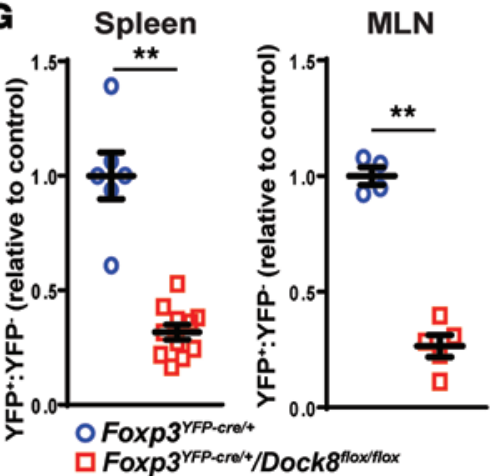

H

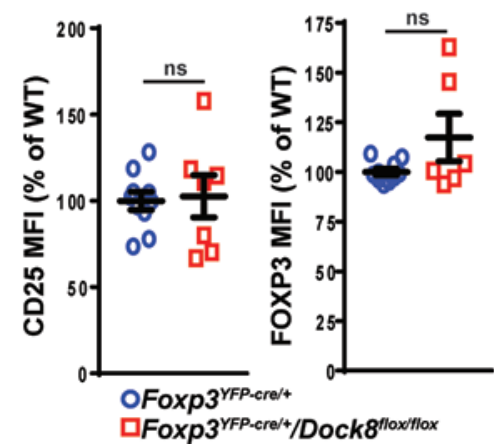

Figure 4. Tregs from mice with a Treg-specific DOCK8 deficiency have impaired fitness. (A and B) Proliferation measured by Cell Trace Violet dilution (A) and IL-2 secretion in culture supernatants (B) by CD4+CD25- Teffs isolated from the spleens of Foxp $3^{\text {YFP-Cre }} /$ Dock $8^{\text {flox/flox }}$ and Foxp $3^{\text {YFP-Cre }}$ control mice cultured for 3 days with anti-CD3+anti-CD28-coated beads. (C) Percentage of YFP+ ${ }^{+}$Tregs of CD4+ $T$ cells and percentage of CD44-CD62 $L^{\text {hi }} r$ Tregs and CD44 ${ }^{+} C D 62 L^{10}$ aTregs among total Tregs in spleens of 30-week-old Foxp $3^{Y F P-C r e} / D o c k 8^{\text {flox/flox }}$ mice and Foxp $3^{\text {YFP-Cre }}$ controls. (D) Percentage of YFP+ ${ }^{+}$cells of total CD4 ${ }^{+}$cells

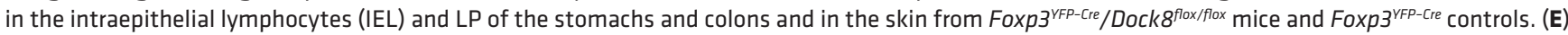
qPCR analysis of Foxp3, II2ra, Tgfb, and I/10 mRNA levels in FACS-sorted CD4+CD25+YFP+ Tregs from Foxp3 $3^{Y F P-C r e} /$ Dock $8^{\text {flox fllox }}$ mice and Foxp3 $3^{\text {YFP-Cre }}$ controls. Results are expressed as fold increase relative to the ratio of the mRNA of interest/b2microglobulin in Foxp3 $3^{Y F P-c r e ~ c o n t r o l s . ~(F) ~ S u p p r e s s i o n ~ o f ~ t h e ~ p r o l i f e r-~}$ ation of $\mathrm{CD} 4^{+} \mathrm{CD} 25^{-}$Teffs stimulated with mitomycin C-treated APCs and soluble anti-CD3 mAb at a Teff/Treg ratio of 1:1. Teff proliferation was measured

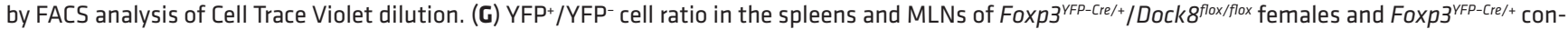
trols normalized to a ratio of 1.0 in the controls. (H) Quantitative analysis of surface CD25 and intracellular FOXP3 protein expression by splenic CD4 ${ }^{+} \mathrm{YFP}{ }^{+}$ cells from Foxp $3^{\mathrm{YFP}-\mathrm{Cre} /+} / D_{\text {ock }} 8^{\text {flox/flox }}$ females and Foxp ${ }^{\mathrm{YFP}-\text { Cre/+ }}$ controls. Results in $\mathbf{A}, \mathbf{B}$, and $\mathbf{F}$ are representative of 3 independent experiments. Symbols represent individual mice, and error bars represent mean and SEM. $t$ test, NS $P>0.05,{ }^{*} P<0.05,{ }^{* *} P<0.01,{ }^{* *} P<0.001$.

data not shown). The percentage of activated $\mathrm{CD} 4^{+} \mathrm{CD} 69^{+} \mathrm{T}$ cells was increased in the peripheral LNs, but not spleens, of Foxp $3^{\text {YFP-Cre } / D o c k 8^{f t o x} / f o x}$ mice compared with Foxp $3^{\text {YFP-Cre }}$ controls (Supplemental Figure $2 \mathrm{D}$ and Figure $2 \mathrm{~F}$ ).

qPCR analysis revealed significantly increased mRNA expression of $I l 17 a$ and $I l 4$, but not $I l 2, I l 5$, Il13, or Ifng, in peripheral LNs from Foxp $3^{Y F P-C r e} /$ Dock $8^{\text {flox } / f l o x}$ mice compared with Foxp $3^{\text {YFP-Cre }}$ controls (Figure $2 \mathrm{G}$ ). Intracellular FACS analysis revealed increased percentages of IL- $17 \mathrm{~A}^{+}$and IL- $4^{+} \mathrm{CD} 4^{+} \mathrm{FOXP} 3$ 
A
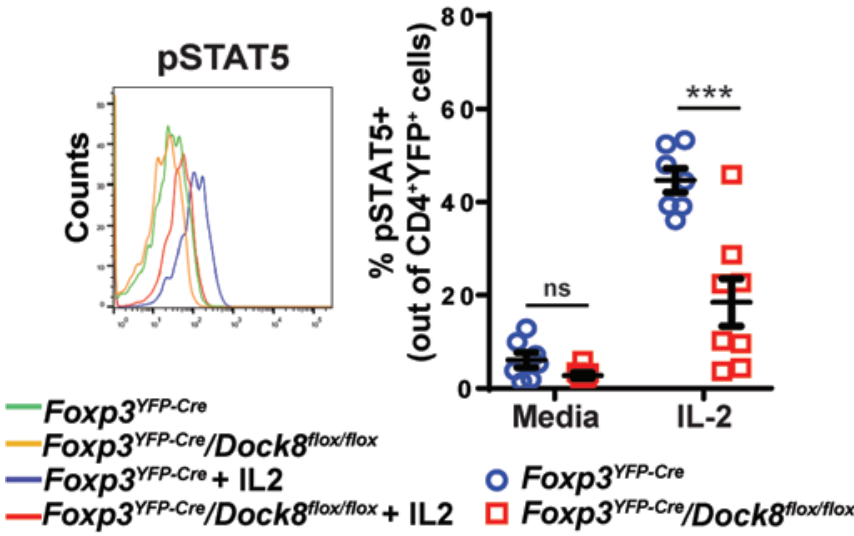

B

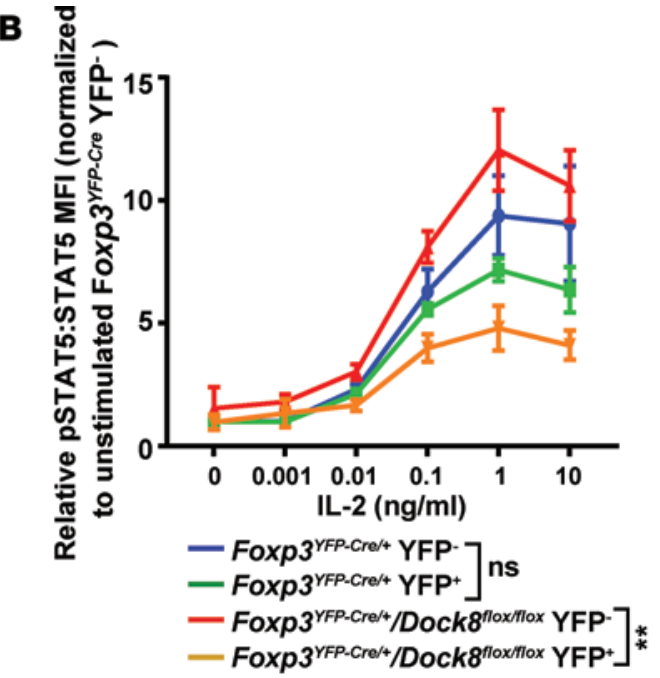

D

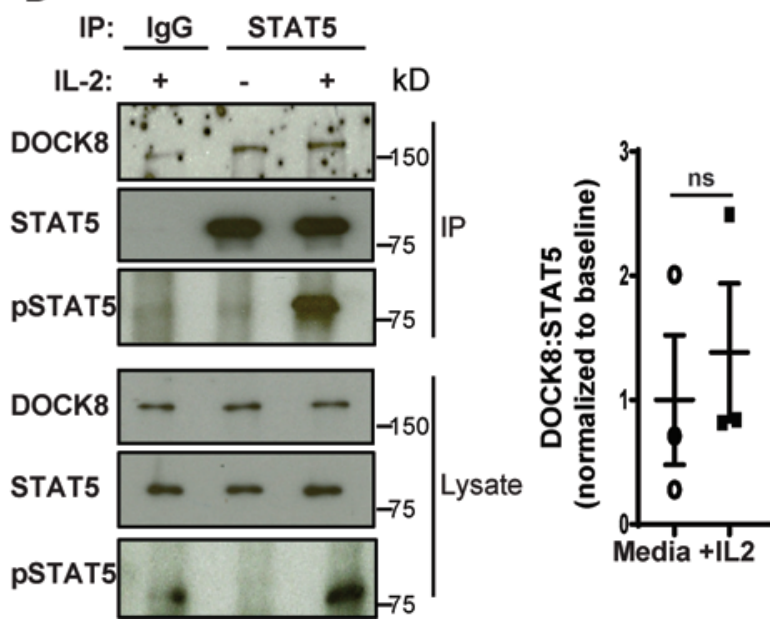

C

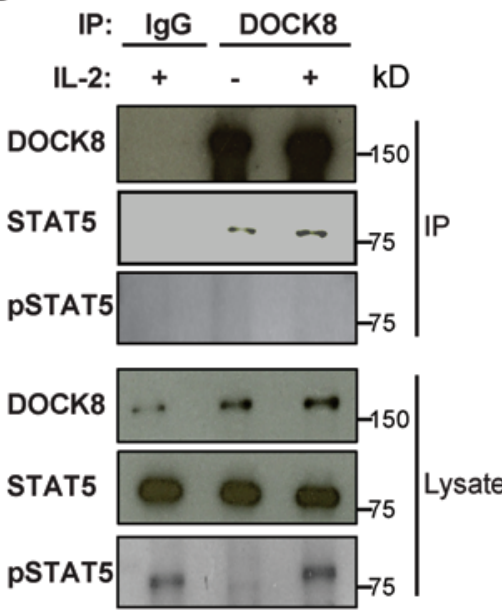

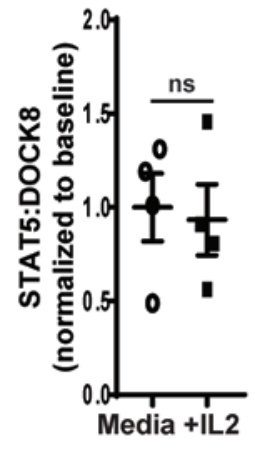

Figure 5. DOCK8-deficient Tregs have decreased IL-2-driven STAT5 phosphorylation, and DOCK8 associated with STAT5. (A) Representative FACS analysis of

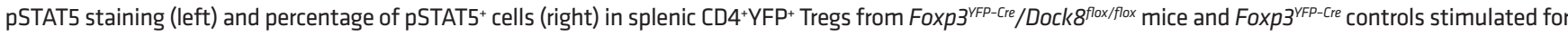

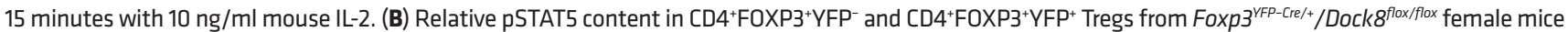
and Foxp $3^{\text {YFP-Cre/+ }}$ controls at baseline and following stimulation with increasing concentrations of IL-2 for 15 minutes. The graph plots the relative pSTAT5/STAT5 MFI ratio normalized to the Foxp $3^{Y F P-C r e /+}$ YFP- Treg baseline ratio. (C) Representative immunoblot of STAT5, pSTAT5, and DOCK8 in DOCK8 immunoprecipitates and cell lysates from WT T cells, and quantification of 4 individual experiments, showing the ratio of immunoprecipitated STAT5/DOCK8. Results were normalized to media alone samples. (D) Representative immunoblot of STAT5, PSTAT5, and DOCK8 in STAT5 immunoprecipitates and cell lysates from WT T cells, and quantification of 3 individual experiments, showing the ratio of immunoprecipitated DOCK8/STAT5. Results were normalized to media-alone samples. Results in $\mathbf{A}$ and $\mathbf{B}$ are representative of 3 independent experiments using 2-3 mice per group in each. Error bars represent the mean and SEM. Significance was determined by unpaired $t$ test in $\mathbf{A}, \mathbf{C}$, and $\mathbf{D}$, while ANOVA was used to compare the curves in $\mathbf{B}$. ns $P>0.05,{ }^{* * *} P<0.001$.

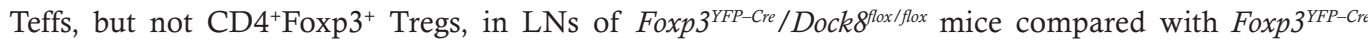
controls (Figure $2 \mathrm{H}$ ), indicating that Teffs, but not Tregs, are the major source of increased cytokine pro-

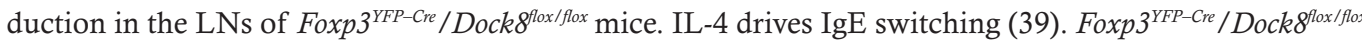
mice had a marked increase in levels of serum IgE (Figure 2I). Serum IgA, but not IgG or IgM, was also significantly elevated (Figure 2I and data not shown). Thus, selective DOCK8 deficiency in Tregs results in the development of lymphoproliferation and $\mathrm{T}$ cell activation, with increased expression of IL-17A and IL-4 cytokines in Teffs in the setting of normal numbers of Tregs in the lymphoid tissues.

Mice with selective DOCK8 deficiency in Tregs develop severe gastrointestinal inflammation. Treg defects are

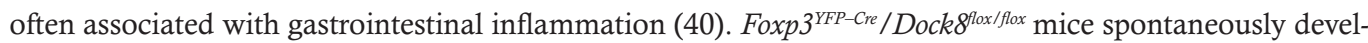
oped enlarged mesenteric LNs (MLNs) by 6-8 weeks of age (Figure 3A). Total cellularity, numbers of $\mathrm{CD} 4^{+} \mathrm{T}$ cells, and the percentage of activated $\mathrm{CD} 4^{+} \mathrm{CD} 69^{+} \mathrm{T}$ cells were all significantly higher in the MLNs

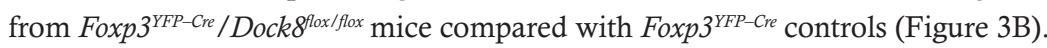




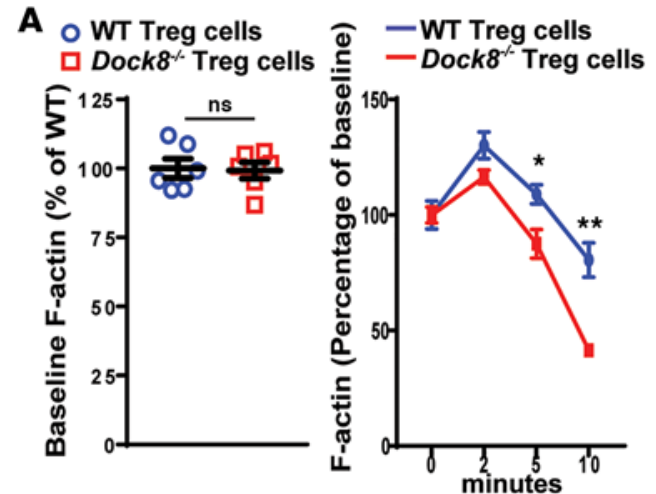

E

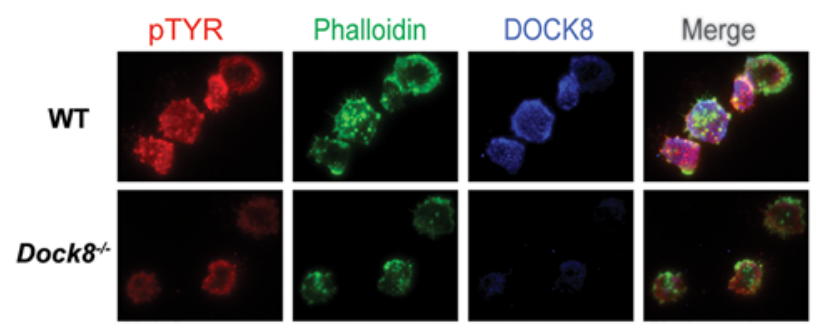

B

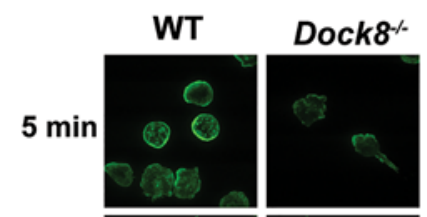

$45 \mathrm{~min}$

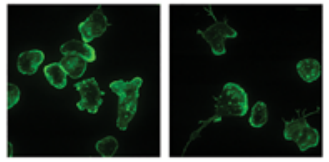

Phalloidin
C

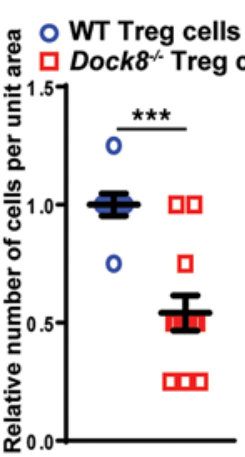

D

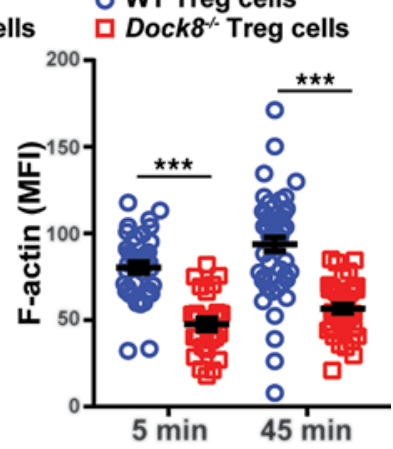

G
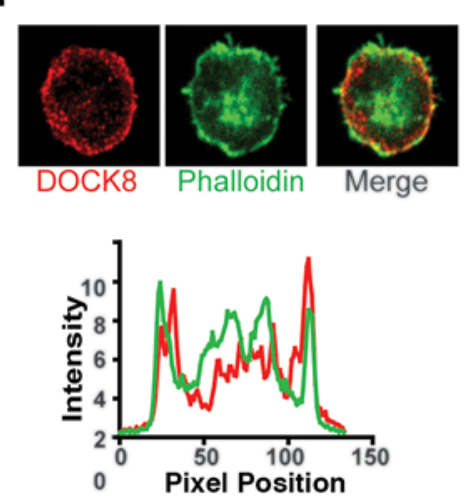

$\mathbf{J}$
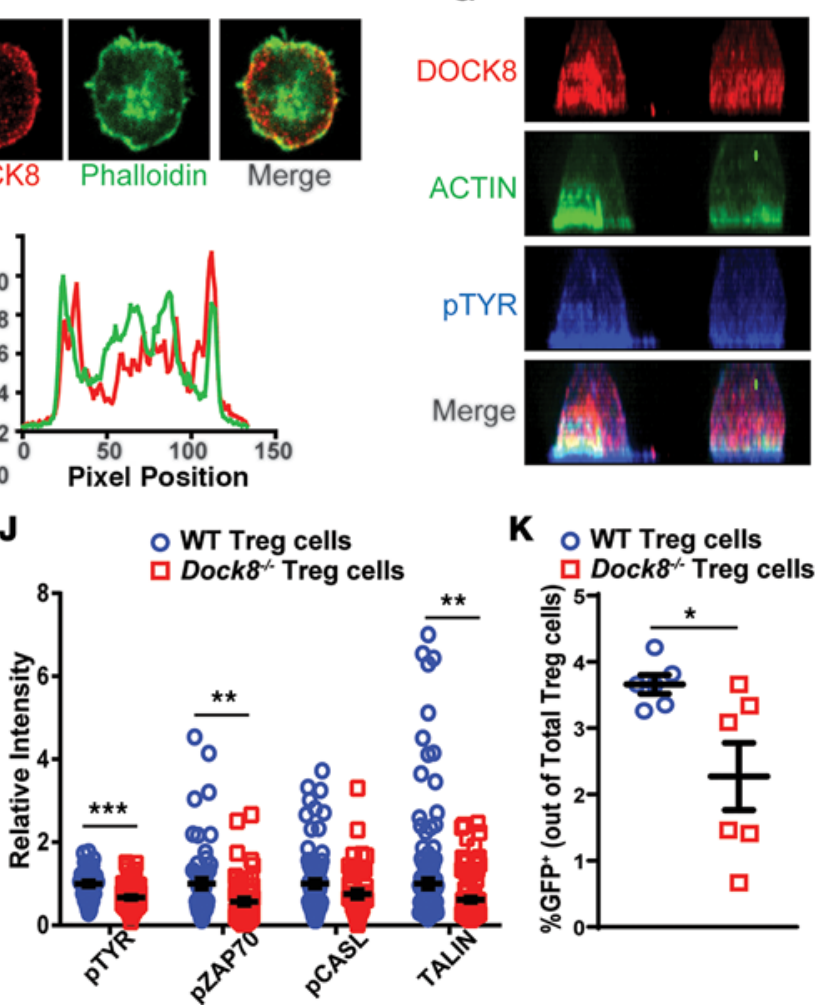

K O WT Treg cells

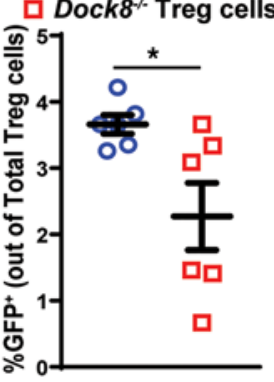
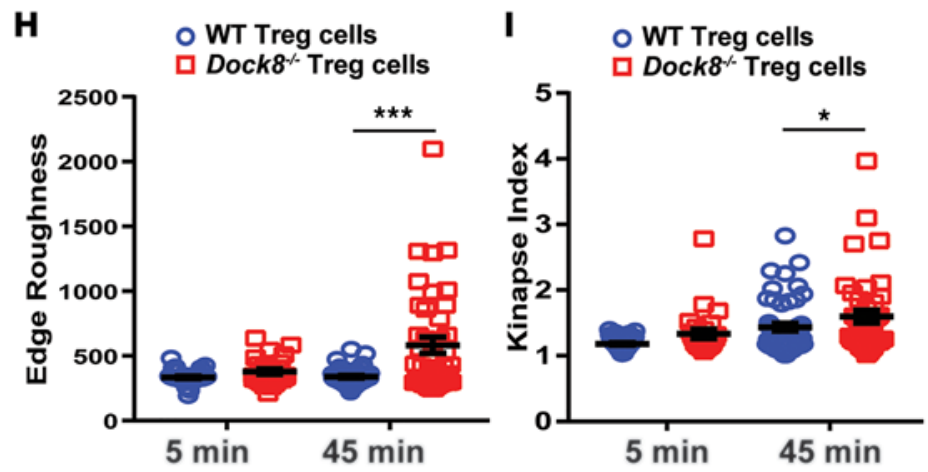

Figure 6. DOCK8-deficient Tregs have abnormal shape and F-actin kinetics and an unstable immune synapse. (A) Baseline F-actin content of CD4 ${ }^{+}$CD25+ Tregs from Dock $8^{-/-}$and WT mice, and effect of CD3 crosslinking on the F-actin content of Tregs from Dock $8^{-1-}$ and WT mice. Results are expressed as the change in the MFI of F-actin from the baseline (time 0). (B) Representative images of CD4+CD25+ Tregs from Dock $8^{-/-}$mice and WT controls plated on anti-CD3- and ICAM-1-coated glass chambers and stained for F-actin by phalloidin at 5 and 45 minutes (original magnification, $\times 100$ ). (C) Relative number of adherent cells per unit area at 5 minutes. (D) Quantitative analysis of F-actin staining of Tregs after 5 and 45 minutes of stimulation. (E) Localization of pTYR, F-actin, and DOCK8 in Dock $8^{-/-}$and WT Tregs at 10 minutes (original magnification, $\left.\times 100\right)$. (F) A representative TIRF image of DOCK8 and actin distribution across the synapse after 10 minutes of synapse formation. The graph shows line scan profiles of DOCK8 and ACTIN across the middle of the cell; the green trace represents ACTIN intensity distribution, and the red trace represents DOCK8 intensity distribution. Note that DOCK8 and ACTIN intensities coincide in the cell periphery, represented by the peaks at the beginning and end of the line scan profiles. (G) Side view of 2 representative T cells, showing the whole cell ACTIN, pTYR, and DOCK8 distribution. Cells stained with DOCK8, pTYR, and ACTIN were imaged using confocal microscopy, and the images show a side view of maximum intensity projection of the confocal images. (H) Quantification of cell edge roughness determined by "shape descriptors" utility of ImageJ at 5 and 45 minutes. (I) Measurement of immune synapse instability, as denoted by the kinapse index (transient interactions index $>1$ ) at 5 and 45 minutes. (J) Relative staining intensity of pTYR, phospho-ZAP70 (pZAP70), and TALIN at 10 minutes. (K) Transendocytosis of CD86-GFP by Tregs from Dock $8^{-/-}$and WT mice cocultured with CD86-GFP-expressing CHO cells. The percentage of GFP+ Tregs of total Tregs is shown. Results in $\mathbf{A}$ and $\mathbf{K}$ are representative of 3 independent experiments. Results in B-J are representative of 2 independent experiments. Symbols represent individual measurements, and error bars represent mean and SEM. Significance was determined by unpaired $t$ test. ns $P>0.05,{ }^{*} P<0.05,{ }^{* *} P<0.01,{ }^{* *} P<0.001$. 
A

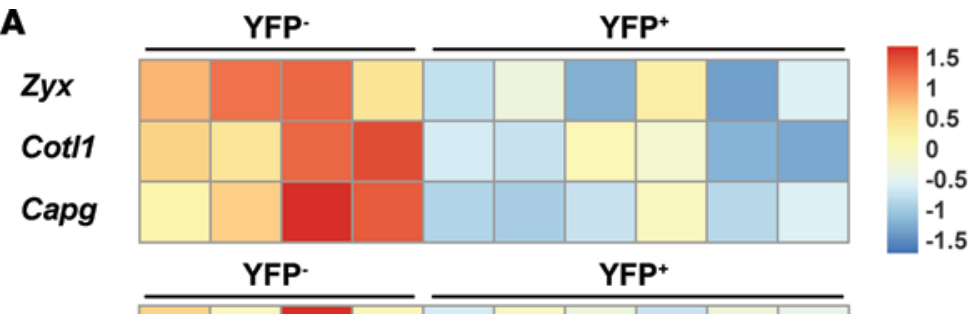

Tgfb2

Itgae

Rgs1

Foxp3

Ccr4

Cxcr6

Id2

Tigit

Pdcd1

Nrp1

Cxcr3

Tnfrsf18

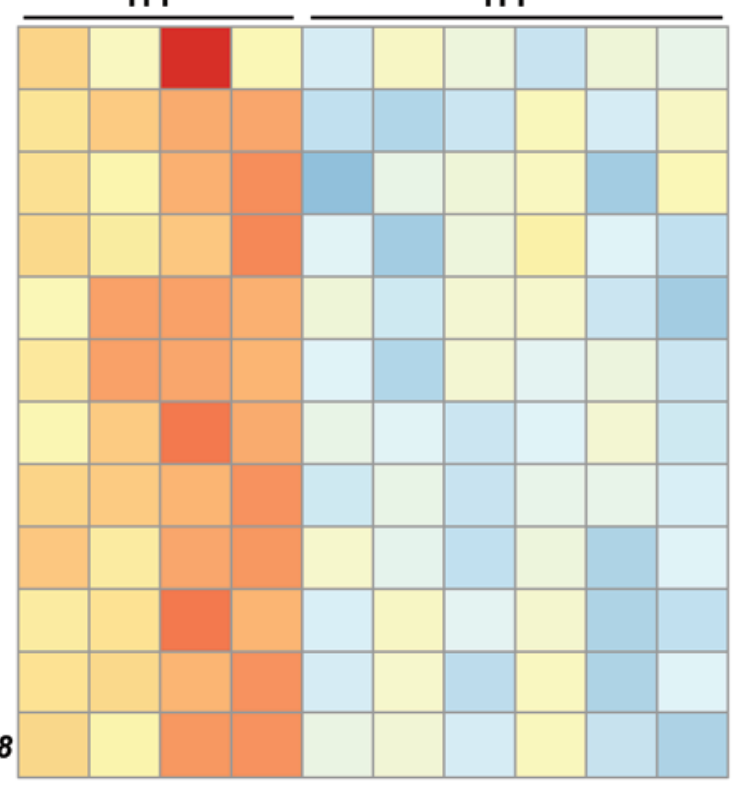

C

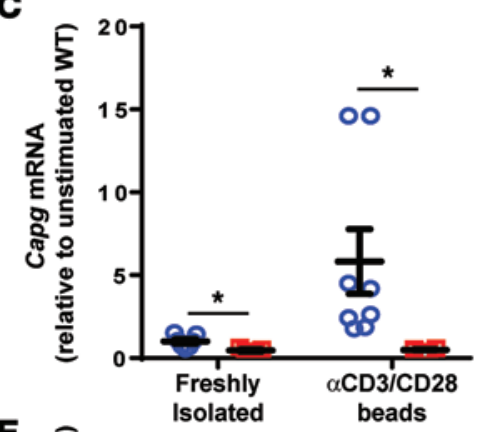

E

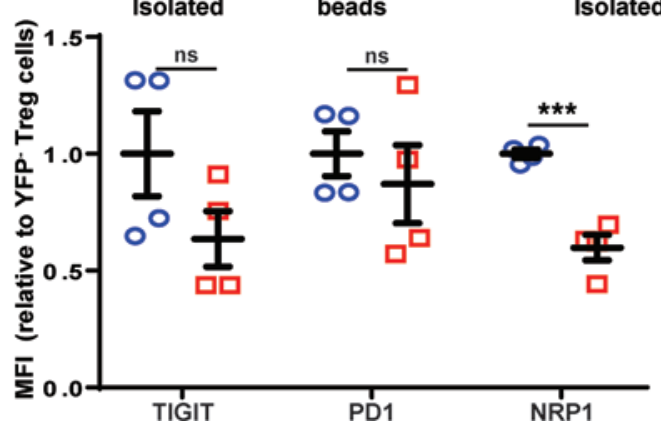

O WT Treg cells
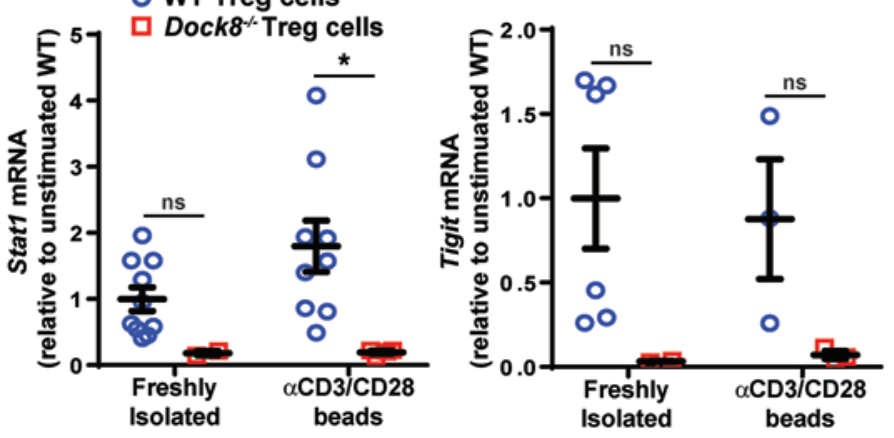

B
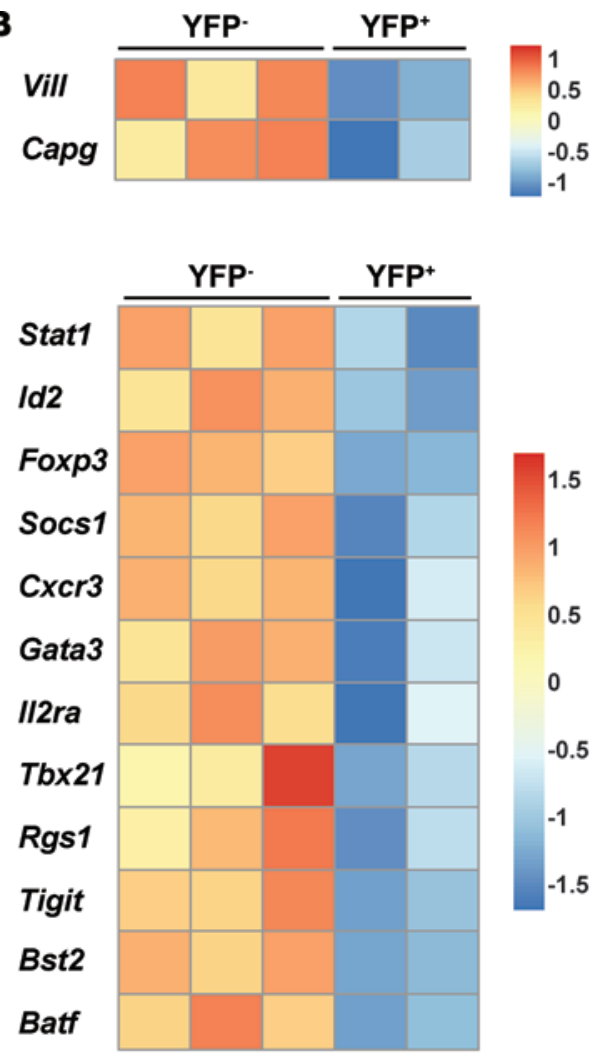

D

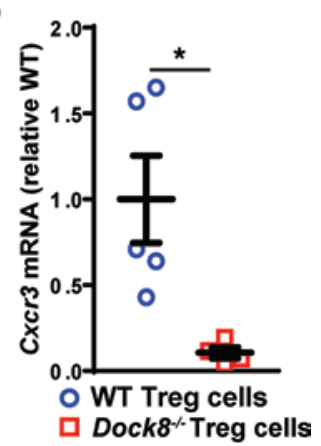

Figure 7. DOCK8-deficient Tregs have decreased expression of cytoskeleton- and Treg-associated genes. (A and $B) C D 4^{+} C D 25^{+} C D 39^{+} Y F P+$

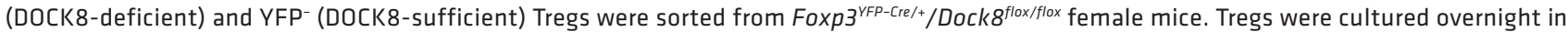
media alone (A) or with anti-CD3+CD28 beads (B). Heatmaps of selected genes differentially expressed in $\mathrm{YFP}^{+}$and $\mathrm{YFP}^{-}$Tregs from Foxp $3^{Y F P-C r e /+}$ Dock $8^{f l o x} / f l o x$ female mice. The cutoff for significance was $P<0.05$. $P$ values were calculated using the Wald test for differential expression analysis. $P$ values were corrected afterward for multiple testing. Expression of genes is centered and scaled by row to highlight differences in each gene sample. Each column represents an individual mouse. (C and D) $C D 4^{+} C D 25^{+} C D 39^{+}$Tregs were FACS sorted from Dock $8^{-/-}$and WT mice. RNA was prepared from Tregs directly after isolation (C) or after 24-hour culture with anti-CD3+CD28 beads (C and D). qPCR results are expressed as fold increase of mRNA of interest/b2microglobulin ratio relative to the unstimulated WT Tregs. (E) MFI of surface marker staining on YFP- DOCK8-sufficient and YFP+ DOCK8-deficient CD4 ${ }^{+} \mathrm{CD} 25^{+}{ }^{+} D 39^{+}$Tregs from Foxp $3^{Y F P-C r e /+} / D o c k 8^{\text {flox/flox }}$ female mice. Symbols represent individual mice. Bars in C-E represent the mean and SEM. $t$ test, NS $P>0.05,{ }^{*} P<0.05,{ }^{* *} P<0.001$. 


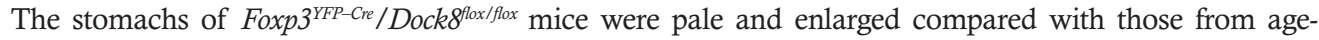
matched Foxp3 $3^{Y F P-C r e}$ controls (Figure 3C). Histologic examination revealed hyperkeratosis of the forestom-

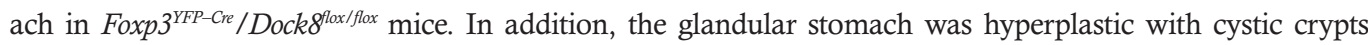
and mononuclear infiltration of the lamina propria (LP) (Figure 3D). Gastric-specific antibodies have long been associated with Treg deficiency in neonatally thymectomized mice $(41,42)$. Gastric autoantibodies were

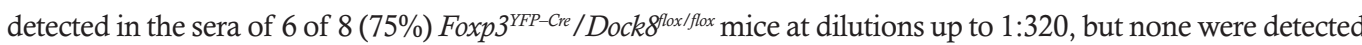
in the sera from 6 age-matched Foxp $3^{Y F P-C r e}$ controls (Figure 3E). Histologic examination of the small intestine

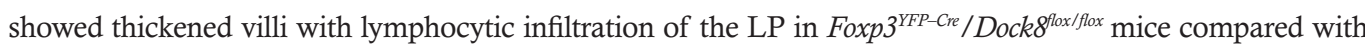

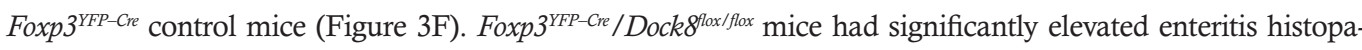
thology scores and an increase in Ifng mRNA expression in the small intestine compared with age-matched Fox$p 3^{Y F P-C r e}$ controls (Figure 3, G and H). The colons from Foxp $3^{Y F P-C r e} /$ Dock $8^{f l o x}$ flox mice had LP densely infiltrated with lymphocytes and plasma cells. Goblet cells were reduced, and the mucosa was markedly thickened (Figure 3I). The colitis histopathology score was significantly elevated in Foxp $3^{Y F P-C r e} /$ Dock $8^{f l o x}$ ffox mice compared with age-matched Foxp $3^{Y F P-C r e}$ controls (Figure 3J). Lipocalin-2 is secreted by neutrophils, and its levels are increased in the feces in murine models of colitis (43). The fecal content of lipocalin-2 was significantly higher

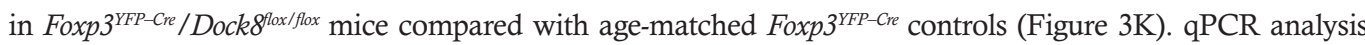
revealed markedly increased expression of Il2, Ifng, Il17a, and Il4 mRNA in the colons of Foxp $3^{Y F P-C r e} /$ Dock $8^{\text {flox/flox }}$ mice compared with Foxp $3^{Y F P-C r e}$ controls (Figure 3L). These data demonstrate that selective DOCK8 deficiency in Tregs results in the development of severe gastrointestinal inflammation.

Tregs from mice with selective DOCK8 deficiency in Tregs have normal in vitro function but impaired fitness. As expected, proliferation and IL-2 secretion by CD4 ${ }^{+} \mathrm{CD} 25^{-}$Teffs following stimulation with anti-

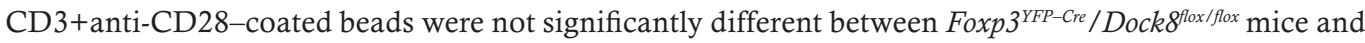
Foxp $3^{Y F P-C r e}$ controls (Figure 4, A and B). There was an increased percentage of total and activated $\mathrm{YFP}^{+}$ Tregs in the spleens and LNs of Foxp $3^{Y F P-C r e} /$ Dock $8^{\text {flox/flox }}$ mice compared with Foxp $3^{\text {YFP-Cre }}$ controls (Figure $4 \mathrm{C}$, Supplemental Figure 3A, and data not shown). However, there was a significant decrease in the percentage of $\mathrm{YFP}^{+}$Tregs among $\mathrm{CD}^{+} \mathrm{T}$ cells in the LP of the inflamed stomachs and colons and among

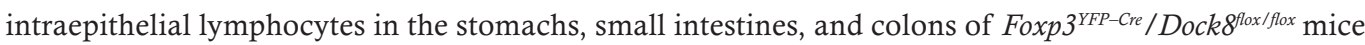
compared with Foxp $3^{Y F P-C r e}$ controls (Figure 4D). In contrast, the percentage of Tregs in the noninflamed skin of Foxp $3^{Y F P-C r e} / D o c k 8^{f l o x}$ flox mice was comparable to that in the skin of Foxp $3^{\text {YFP-Cre }}$ controls (Figure 4D). These results suggest that DOCK8 is important for the homeostasis of Tregs in the inflamed gut.

Expression of CD25, FOXP3, CTLA-4, CD39, and HELIOS was comparable in CD4 ${ }^{+} \mathrm{YFP}^{+}$Tregs from

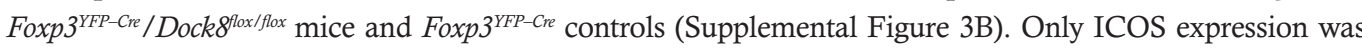

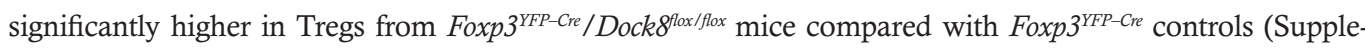
mental Figure 3B), suggestive of activation-induced Treg instability (44). Foxp3, Il2ra, and Tgfb, but not Il10, mRNA levels were significantly lower in sorted CD4 ${ }^{+} \mathrm{YFP}^{+}$Tregs from Foxp $3^{\text {YFP-Cre }} /$ Dock $8^{\text {flox/flox }}$ mice compared with Foxp $3^{Y F P-C r e}$ controls (Figure $4 \mathrm{E}$ ). The ability of $\mathrm{CD}^{+} \mathrm{YFP}^{+}$Tregs from Foxp $3^{Y F P-C r e} /$ Dock $8^{\text {flox } f f o x}$ mice to suppress the proliferation of WT Teffs in response to stimulation with anti-CD3 beads and APCs was comparable to that of $\mathrm{CD}^{+} \mathrm{YFP}^{+}$Tregs from Foxp $3^{Y F P-C r e}$ controls (Figure 4F), suggesting that cell-extrinsic factors affected the decreased in vitro-suppressive activity observed in Tregs from Dock $8^{-1}$ mice (Figure 1G).

We examined the fitness of DOCK8-deficient Tregs by comparing the ratio of DOCK8-deficient

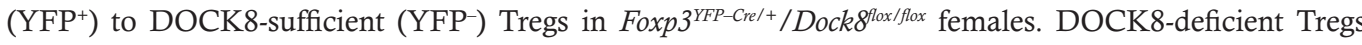
demonstrated a competitive disadvantage compared with DOCK8-sufficient Tregs in populating the spleen and LNs, as evidenced by a significantly lower ratio of $\mathrm{CD}^{+} \mathrm{FOXP}^{+} \mathrm{YFP}^{+}$cells to $\mathrm{CD} 4^{+} \mathrm{FOXP} 3^{+} \mathrm{YFP}^{-}$

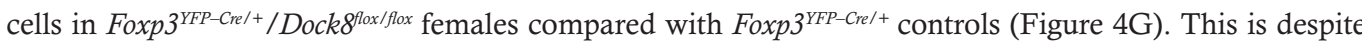
comparable expression of CD25 and FOXP3 by CD4 ${ }^{+} \mathrm{YFP}^{+}$Tregs from Foxp $3^{\text {YFP-Cre/+ }} /$ Dock $^{\text {flox flox }}$ females and Foxp $3^{\text {YFP-Cre/+ }}$ female control mice (Figure $4 \mathrm{H}$ ).

DOCK8-deficient Tregs have defective IL-2-driven STAT5 phosphorylation, and DOCK8 constitutively associates with STAT5. STAT5 phosphorylation in Tregs is important for the ability of Tregs to suppress autoreactive Teffs (45). IL-2 stimulation of splenic Tregs resulted in a significantly lower percentage of phosphorylated $\operatorname{STAT}^{+}\left(\mathrm{pSTAT}^{+}\right)$cells in Foxp $3^{Y F P-C r e} /$ Dock $^{\text {flox/flox }}$ mice compared with Foxp $3^{\text {YFP-Cre }}$ controls (Figure 5A). As expected, IL-2-driven STAT5 phosphorylation was comparable in CD4 ${ }^{+} \mathrm{YFP}^{-}$DOCK8-sufficient Teffs from the two strains (Supplemental Figure 4A). pSTAT5 content following IL-2 stimulation was substantially lower in $\mathrm{YFP}^{+}$Tregs compared with YFP- Tregs in Foxp $3^{\text {YFP-Cre/+ }} /$ Dock $8^{f l o x / f l o x}$ female mice, which had no evidence of inflammation, but was not significantly different between $\mathrm{YFP}^{+}$and $\mathrm{YFP}^{-}$Tregs in Foxp $3^{\text {YFP-Cre/+ }}$ controls 
(Figure 5B). These results indicate that inflammation was not the cause of the impaired response to IL-2 by the Tregs of Foxp $3^{Y F P-C r e} / D o c k 8^{f l o x} / f$ lox mice and support a cell-intrinsic role for DOCK8 in IL-2-driven STAT5 phosphorylation in Tregs. IL-2-induced STAT5 phosphorylation was impaired in $\mathrm{CD}^{+} \mathrm{FOXP} 3^{+}$Tregs as well as $\mathrm{CD}^{+} \mathrm{FOXP}^{-}$Teffs from $\mathrm{Dock}^{-/-}$mice (Supplemental Figure 4, B and C), suggesting that the role of DOCK8 in IL-2-driven STAT5 phosphorylation is not restricted to Tregs.

The impaired IL-2-driven STAT5 signaling in DOCK8-deficient Tregs prompted us to investigate whether DOCK8 and STAT5 associate. STAT5 was detected in DOCK8 immunoprecipitates, but not IgG isotype control immunoprecipitates, from lysates of unstimulated WT splenic T cells (Figure 5C). pSTAT5 was not detected in DOCK8 immunoprecipitates, suggesting that STAT5 dissociates from DOCK8 once phosphorylated (Figure 5C). In reciprocal experiments, DOCK8 coprecipitated with STAT5 from lysates of WT T cells (Figure 5D). IL-2 stimulation did not alter the association of DOCK8 with STAT5 in T cells (Figure 5, C and D). These results demonstrate that DOCK8 and STAT5 associate constitutively.

DOCK8-deficient Tregs form an unstable IS and have decreased transendocytosis of the costimulatory molecule CD86. DOCK8-deficient CD4 ${ }^{+} \mathrm{T}$ cells and DCs show impaired migration through tissues $(14,16,46)$. Localization of Tregs in T cell-rich areas of LNs is important for controlling autoreactive Teff clones (45). We used fluorescence-based immunohistology to examine the localization of DOCK8-deficient Tregs in the LNs. In these experiments, we utilized LNs from 4-week-old Foxp $3^{Y F P-C r e}$ controls and Foxp $3^{Y F P-C r e} / D o c k 8^{f f o x} / f \circ x$ mice prior to the onset of lymphadenopathy. Similar to DOCK8-sufficient Tregs, DOCK8-deficient Tregs were found primarily in the T cell-rich zone of LNs (Supplemental Figure 5A), demonstrating that DOCK8 deficiency does not have a detectable effect on the gross localization of Tregs in LNs.

The ability to form a stable IS is essential for the proper function of Tregs $(10,47)$. IS formation is dependent on TCR/CD3-driven F-actin reorganization (48). There was no significant difference in baseline F-actin content between Dock8 ${ }^{-1}$ and WT Tregs (Figure 6A). TCR/CD3 crosslinking caused an increase in $\mathrm{F}$-actin at 2 and 5 minutes after stimulation in WT Tregs, followed by a decrease in F-actin content to below baseline at 10 minutes (Figure 6A). The F-actin content of Tregs from Dock $8^{-1-}$ mice was lower at 2, 5, and 10 minutes compared with control WT Tregs (Figure 6A).

To examine the role of DOCK 8 in the IS, $\mathrm{CD} 4{ }^{+} \mathrm{CD} 25^{+}$Tregs were plated on glass coverslips coated with anti-CD3 mAb and ICAM-1 to mimic the interaction between Tregs and APCs. Total internal reflection fluorescence (TIRF) microscopic examination of the $\mathrm{T}$ cell-coverslip interface revealed that fewer Tregs adhered to the coverslip and formed a synapse (Figure 6, B and C). Dock $8^{-1-}$ Tregs that sustained a synapse exhibited significantly reduced actin polymerization in response to TCR and LFA1 engagement (Figure $6, \mathrm{~B}, \mathrm{D}$, and $\mathrm{E}$ ). The reduced $\mathrm{F}$-actin content after the short incubation ( 5 minutes) could not be recovered after a longer (45-minute) duration of contact with the coverslips (Figure 6D). Lamellar F-actin staining was markedly reduced in DOCK8-deficient cells (Figure 6E). Importantly, DOCK8 colocalized with the lamellar F-actin ring at the IS in WT Tregs (Figure 6, F and G). In addition to decreased F-actin accumulation, Dock $8^{-1-}$ Tregs exhibited aberrant morphology, as determined by measurement of edge roughness; this was especially apparent after 45-minute incubation with the coverslip (Figure 6, B, E, and H).

A stable IS between Tregs and DCs is important for transendocytosis $(49,50)$, the process by which CTLA-4-expressing Tregs acquire the costimulatory molecules CD80 and CD86 from DCs, thereby decreasing the costimulatory function of DCs, rendering them tolerogenic. Following the decrease in costimulatory molecules on the DC, Tregs become increasingly motile and move on to form transient interactions with other DCs (51). This sampling behavior with rapidly dissolving and reforming IS is termed "kinapse" (52). Dock8 ${ }^{-1}$ Tregs that adhered to anti-CD3 and ICAM-1 bilayers had similar synapse areas as WT control Tregs (Supplemental Figure 5B). However, Dock $8^{-1-}$ Tregs demonstrated a significantly higher incidence of kinapses, characterized by an elongated, polarized morphology (Figure 6, B and I), a reflection of a motile synapse. These data suggest that DOCK8-deficient Tregs are impaired in their ability to maintain a stable IS with APCs.

TCR-driven IS formation is characterized by the accumulation of tyrosine phosphorylated proteins (pTYR) that include the TCR signal transducer ZAP70 and the mechanosensor CASL $(53,54)$. Accumulation of total pTYR proteins, pZAP70, and pCASL was reduced in the IS of Tregs from Dock8 ${ }^{-1-}$ mice compared with control WT Tregs (Figure 6I). TCR/CD3 ligation causes conformational changes in LFA-1 via inside-out signaling that promote adhesiveness to ICAM-1 (55). TALIN, a protein that binds to integrins, as well as DOCK8, accumulates at the IS of T cells $(56,57)$. Consistent with reduced adhesion, the accumulation of TALIN in the IS was significantly reduced in Tregs from Dock $8^{-1-}$ mice compared with control 
Tregs (Figure 6J). These findings suggest a qualitative defect in the IS of DOCK8-deficient Tregs associated with defective early signaling, synapse stability, and mechanotransduction.

Transendocytosis by Tregs was assessed by examining GFP acquisition by Tregs cocultured for 24 hours with $\mathrm{CHO}$ cells stably expressing a CD86-GFP fusion protein in the presence of anti-CD3+antiCD28-coated beads. The percentage of Tregs from Dock8 ${ }^{-1-}$ mice that acquired GFP was significantly lower than that of Tregs from WT controls (Figure 6K). This difference was not due to a difference in surface CTLA-4 expression, which was comparable in anti-CD3+anti-C28-stimulated Tregs from Dock8 ${ }^{-1}$ mice and WT controls (Supplemental Figure 5C).

Altered gene expression in DOCK8-deficient Tregs. We examined the effect of DOCK8 deficiency on gene expression by Tregs. Tregs were sorted from Foxp $3^{\text {YFP-Cre/+}} / D o c k 8^{f l o x}$ flox female mice. CD $4^{+} \mathrm{CD} 39^{+} \mathrm{CD} 25^{+} \mathrm{YFP}^{+}$ (DOCK8-deficient) and $\mathrm{CD} 4{ }^{+} \mathrm{CD} 39^{+} \mathrm{CD} 25^{+} \mathrm{YFP}^{-}$(DOCK8-sufficient) Tregs were cultured for 24 hours in medium alone or medium with anti-CD3+anti-CD28 beads. RNAseq was performed on RNA isolated from $\mathrm{YFP}^{+}$and $\mathrm{YFP}^{-}$Tregs after culture. Differential expression of Dock8 exons in $\mathrm{YFP}^{-}$cells and $\mathrm{YFP}^{+}$cells was observed and confirmed appropriate removal of exons 44-46 in $\mathrm{YFP}^{+}$DOCK8-deficient cells (Supplemental Figure 6). The numbers of genes differentially expressed in $\mathrm{YFP}^{+}$(DOCK8-deficient) Tregs compared with YFP- (DOCK8-sufficient) Tregs were 123 before stimulation (112 genes were downregulated) and 162 (128 genes were downregulated) after stimulation. We focused our analysis on actin cytoskeleton- and Treg-related genes. Several of these genes were underexpressed, whereas none were overexpressed in DOCK8-deficient Tregs. Actin cytoskeleton-related genes included with decreased expression included Vill, Capg, Zyx, and Cotl1, which encode proteins that localize with F-actin and either bind F-actin directly and/or regulate its assembly (refs. 58-60 and Figure 7, A and B). Treg transcription factors with differential expression included Foxp3, Stat1, Tbx21, Id2, and Gata3, which are involved in the polarization and stabilization of the Treg phenotype (61-63). Other Treg-related genes included Tgfb2, Tigit, Tnfrsf18, and Il2ra, which are involved in Treg-suppressive activity (64-66), and genes that encode markers of Tregs and Treg subsets or enable tissue homing, including Nrp1, Rgs1, Bst2, Batf, Pdcd1, Itgae, Socs1, Cxcr3, Ccr4, and Cxrc6 (Figure 7, A and B, and refs. 61, 67-75). Decreased expression of the IL-2-regulated genes Foxp3, Il2ra, Tnfrsf18, Socs1, and Cxcr3 in Dock8 ${ }^{-1-}$ Tregs is consistent with impaired IL-2-driven STAT5 phosphorylation in these cells. The decreased levels of Capg, Foxp3, Il2ra, Stat1, Tigit, and Cxcr3 in Dock8 ${ }^{-1}$ Tregs was confirmed by qPCR analysis of mRNA (Figure 1F and Figure 7, C and D). In addition, reduced surface expression of TIGIT, PD1, and NRP1 was observed on $\mathrm{YFP}^{+}$DOCK8-deficient Tregs compared with YFP- DOCK8-sufficient Tregs from Foxp $3^{Y F P-C r e /+} /$ Dock $8^{\text {flox/flox }}$ female mice (Figure 7E).

\section{Discussion}

Our findings establish that DOCK8 expression in Tregs is critical for peripheral self-tolerance. Mice with selective deficiency of DOCK8 in Tregs develop spontaneous lymphoproliferation and autoimmune disease. DOCK8-deficient Tregs had impaired IL-2-driven STAT5 phosphorylation, abnormalities in TCR actin dynamics, an unstable IS, and diminished transendocytosing, all of which are important for the ability of Tregs to maintain tolerance.

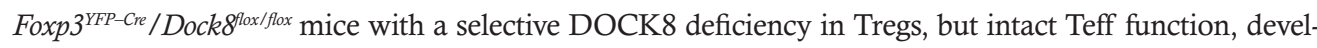
oped spontaneous inflammation and autoimmunity at a young age. This is evidenced by their failure to gain weight and the development of anemia, progressive lymphoproliferation, elevated serum amyloid P levels, increased numbers of activated CD4 ${ }^{+} \mathrm{T}$ cells, and increased expression of $I l 17 a$ and Il4 mRNA in their LNs.

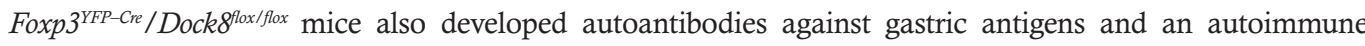
gastroenteropathy characterized by a dense lymphocytic infiltrate in the LP throughout the gut. The small

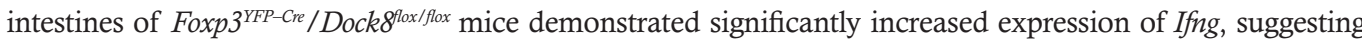
a role for Th1-mediated inflammation in driving enteritis, while colons demonstrated significantly increased expression Il2, Ifng, Ill7a, and Il4 mRNA, suggesting that multiple cytokines were involved in driving colitis in

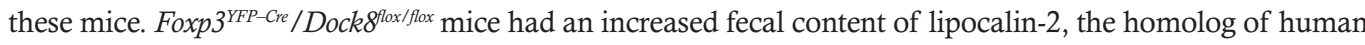
N-GAL, which is present in high levels in the stools of patients with colitis $(43,76)$. While colitis developed in

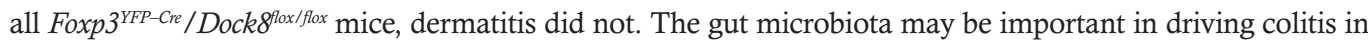
these mice, as in other models of autoimmune enteropathy (77-79). Together, these findings suggest that Treg dysfunction may play a role in the colitis that develops in patients with DOCK8 deficiency (80).

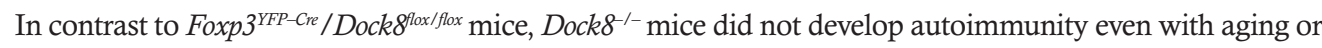
chronic stimulation with poly(I:C) to mimic microbial infection. We similarly found no signs of spontaneous autoimmunity in CD4-Cre/Dock $8^{f l o x} f$ fox mice, which lack DOCK8 in both Teffs and Tregs (E. Janssen and R.S. 
Geha, unpublished observations). These findings support the hypothesis that DOCK8 function in Teffs is crucial for the establishment of autoimmunity in the context of DOCK8-deficient Tregs and may explain the low prevalence of autoimmunity in DOCK8-deficient patients. Decreased availability of IL-2 from Teffs together with impaired IL-2-driven STAT5 activation may have contributed to the decreased percentage of Tregs and impaired in vitro-suppressive ability of Tregs from Dock $8^{-1-}$ mice. In contrast, Foxp $3^{Y F P-C r e} / D o c k 8^{\text {flox/flox }}$ mice, in which IL-2 production by Teffs was intact, had normal or elevated percentages of Tregs in lymphoid organs and normal Treg in vitro-suppressive activity.

A role for DOCK8 in the maintenance of Tregs is supported by the competitive disadvantage of $\mathrm{YFP}^{+}$DOCK8-deficient Tregs compared with YFP ${ }^{-}$DOCK8-sufficient Tregs in populating the lymphoid

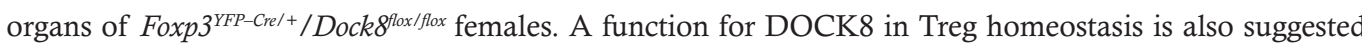
by the significant decrease in the percentage of Tregs in the inflamed stomach and colon, but not the unin-

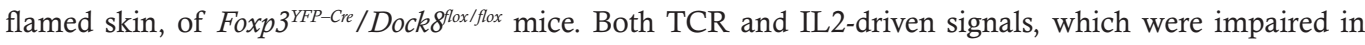
DOCK8-deficient Tregs, are important for the competitiveness and fitness of Tregs $(7,8,10,47)$.

There was a significant decrease in baseline and IL-2-induced STAT5 phosphorylation in Tregs from Fox-

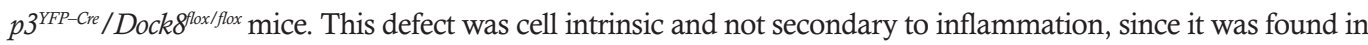

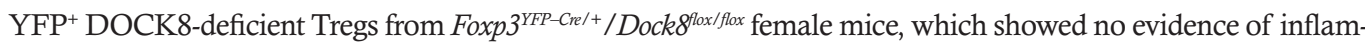
mation. The IL-2 signaling defect in Tregs may have contributed to the development of autoimmune disease

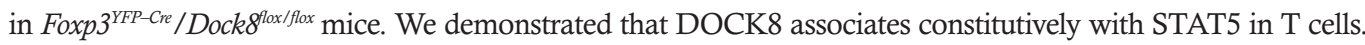
This association is not increased by IL-2 stimulation. DOCK8 may bring STAT5 in proximity to the IL-2R facilitating STAT5 phosphorylation by receptor-associated JAK kinases. DOCK8 exists in T cells in a high-molecular-weight complex that contains proteins that include WASP, WIP, and TALIN $(16,57)$. The association of DOCK8 and STAT5 in T cells may be direct or may be mediated by one of the other proteins in this complex.

DOCK8-deficient Tregs had impaired ability to increase their F-actin content in response to TCR/ CD3 ligation, exhibited defective adhesion to anti-CD3- and ICAM-1-coated coverslips, and displayed shape abnormalities over time compared with WT Tregs. Using an anti-CD3 and ICAM-1 system designed to mimic the Treg and DC interaction, we found that DOCK8 localizes to the lamellar actin ring in Tregs. DOCK8-deficient Tregs formed a less stable IS and were more prone to transient kinapse formation. This was accompanied by decreased recruitment to the IS of phosphotyrosine proteins, including phospho-ZAP70. In addition, accumulation at the IS of the mechanosensor pCASL, which is essential for the establishment of IS stability (81), and of TALIN, a known DOCK8 interactor crucial for IS stability, was reduced in Dock8 ${ }^{-1-}$ Tregs. DOCK8-deficient Tregs were significantly less efficient at transendocytosis of CD86 from $\mathrm{CHO}$ cells, a system that relies on Treg interactions with CD86 exclusively These findings suggest that DOCK8 has a critical role in the formation of a stable IS between Tregs and DCs and in transendocytosis.

Gene expression analysis by RNAseq suggested that DOCK8 plays a role in the expression of several cytoskeletal proteins important for actin assembly, IS stability, adhesion, and motility (58-60). DOCK8-deficient Tregs demonstrated decreased expression of several IL-2-regulated genes that included Foxp3 and Il2ra, consistent with impaired IL-2-driven STAT5 phosphorylation. There was also decreased expression of several transcription factors that affect Treg stability and subset development $(62,67,68,72,74,82,83)$. This may be relevant to the rampant Th1/Th17 intestinal inflammation observed in Foxp $3^{\text {YFP-Cre } / D o c k 8^{f o x} / f l o x}$ mice. We did not observe a change in the expression of genes previously shown to be differentially expressed in Tregs lacking TCR expression (47), suggesting that TCR signals affecting gene expression remain intact in the absence of DOCK8.

In summary, our findings suggest that DOCK8 is important for IL-2 signaling, TCR-driven actin remodeling, IS stability, and transendocytosis in Tregs and, thereby, Treg function in maintaining of peripheral immunological tolerance.

\section{Methods}

Mice. The generation of Dock8 $8^{-1}$ mice is described in ref. 16. To generate Dock8 conditional knockout mice, intron 43-44 to 46-47 were amplified by PCR from the genomic DNA of 129 ES cells. The 3.15-kb 5' arm, $6.5-\mathrm{kb} \mathrm{3}$ ' arm, and a 5.4-kb sequence containing exons 44-46 were cloned into the pEZ-Frt-Lox-DT vector (Supplemental Figure 2A). Mice were generated using standard techniques and mated with mice expressing the Flp recombinase under the Rosa promoter to remove the neo gene and then backcrossed with C57BL/6

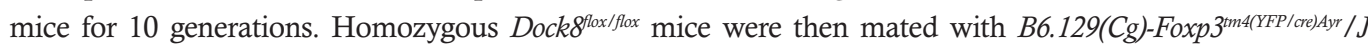


mice (Jackson Laboratories) to generate mice with a Treg-specific deficiency in DOCK8. Both female and male mice were studied, and sex matching was done between comparison groups. All mice were kept in a specific pathogen-free environment. Unless otherwise indicated 3 mice were in all comparison groups, and individual experiments were repeated at least 3 times. No randomization was performed.

Autoantibody detection. Prepared slides with HEp-2 cells and mouse stomach tissues were obtained from Trinity Biotech. Serum was diluted in PBS and applied to each slide for 30 minutes. Slides were washed with PBS $+1 \%$ Tween, and bound IgG was detected with anti-mouse IgG conjugated to Alexa Fluor 488 (Biolegend). Samples were scored by 3 blinded individuals.

Flow cytometry. Single-cell suspensions were made of the thymuses, spleens, and LNs; red blood cells were lysed using ACK lysis buffer. For staining of surface molecules, cells were incubated on ice with fluorochrome-conjugated mAbs against CD4 (clone GK1.5), CD8 (clone 53-6.7), CD45.2 (clone 104), CD25 (clone PC61), CD44 (clone IM7), CD62L (clone MEL-14), CD39 (clone Duha59), CD69 (clone H1.2F3), and ICOS (clone C398.4A) (Biolegend). For intracellular staining with antibodies against HELIOS (22F6), FOXP3 (FJK-16s), and CTLA-4 (UC10-4B9), cells were fixed, permeabilized, and stained according to the manufacturer's directions (Affymetrix).

For intracellular cytokine staining, cells were either stimulated with anti-CD3+anti-CD28 dynabeads (ThermoFisher) for 2 days followed by the addition of Golgistop and Golgiplug (BD Biosciences) for 16 hours or were stimulated with phorbol 12,13-dibutyrate and ionomycin (Sigma-Aldrich) in the presence of Golgistop and Golgiplug for 3.5 hours. They were then fixed and permeabilized using the BD Bioscience Cytofix/Cytoperm kit and incubated with fluorochrome-conjugated antibodies against IL-2 (JES6-5H4), IL-17A (eBio17B7), and IL-4 (11B11) (Affymetrix).

All data were acquired on a BD LSRFortessa cell analyzer using FACSDiva software (BD Biosciences). Analyses were performed using FlowJo software (Tree Star Inc.).

Preparation of intraepithelial lymphocytes and LP cells. The stomach and colon were isolated and flushed with PBS $+1 \%$ FBS on ice. After mincing with scissors, the epithelial layer was stripped by agitation in 10 mM EDTA at $37^{\circ} \mathrm{C}$. This was followed by collagenase VIII digestion (Sigma-Aldrich) and mechanical disruption to free the LP cells. Specimens were enriched for lymphocytes with a $40 \%$ Percoll gradient, before analysis by flow cytometry as detailed above.

Treg suppression assays. $\mathrm{CD}^{+} \mathrm{T}$ cells were isolated by negative selection using the $\mathrm{CD} 4^{+} \mathrm{T}$ cell isolation kit (Miltenyi Biotec) according to the manufacturer's directions. $\mathrm{CD} 4{ }^{+} \mathrm{CD} 25^{-}$Teffs were isolated by depleting $\mathrm{CD} 25^{+}$cells using anti-CD25-biotin and anti-biotin magnetic beads (Miltenyi Biotec). Teffs were labeled with Cell Trace Violet (Life Technologies) to monitor cell divisions by flow cytometry. Tregs were isolated by fluorescent cell sorting for $\mathrm{CD} 4{ }^{+} \mathrm{CD} 25^{+} \mathrm{CD} 39^{+}$Tregs or $\mathrm{CD} 4{ }^{+} \mathrm{CD} 25^{+} \mathrm{CD} 39^{+} \mathrm{YFP}^{+}$Tregs. For preactivation of Tregs, cells were cultured for 48 hours with anti-CD3+anti-CD28 dynabeads (ThermoFisher) at a ratio of 1 bead/1 Treg in the presence of $20 \mathrm{ng} / \mathrm{ml} \mathrm{IL}-2$ (R\&D Systems). Tregs were then washed several times, the dynabeads were removed with a magnet, and Tregs were recounted before their addition to Teff cultures. Teffs were stimulated with anti-CD3 mAb $(1 \mu \mathrm{g} / \mathrm{ml}, 2 \mathrm{C} 11$, Affymetrix $)$ in the presence of $\mathrm{T}$ cell-depleted splenocytes treated with $25 \mu \mathrm{g} / \mathrm{ml}$ mitomycin C (Santa Cruz Biotechnology). On day 4, Teff division was evaluated by flow cytometry.

Cellular proliferation and IL-2 secretion. $\mathrm{CD}^{+} \mathrm{CD} 25^{-}$Teffs were isolated using magnetic beads (Miltenyi) and labeled with Cell Trace Violet as described above. Prepared Teffs were stimulated with anti-CD3+antiCD28 beads (Invitrogen) at a ratio of 1 bead/ 1 cell in round bottom wells. After 72 hours in culture, supernatants were harvested and IL-2 content was measured by ELISA (Affymetrix). An equal volume of complete media was added back to each well, and proliferation was evaluated by flow cytometry on day 4 of culture.

Equivalent numbers of $\mathrm{CD} 4{ }^{+} \mathrm{CD} 25^{+} \mathrm{CD} 39^{+}$Tregs were stimulated with IL-2 at the indicated concentrations and/or anti-CD3+anti-CD28 beads (Invitrogen). After 6 days in culture, $\mathrm{T}$ cells were analyzed by FACS for viability, and cell numbers were normalized using Precision Count beads (Biolegend).

Immunoglobulins and protein assays. Serum IgM, IgG, IgA, and IgE levels were measured by ELISA using capture and detection antibodies from Southern Biotech. Serum amyloid P and haptoglobin (Genway) and stool lipocalin-2 (R\&D Systems) levels were measured by ELISA. For the lipocalin-2 ELISA, fresh fecal samples were vortexed with PBS $+0.1 \%$ Tween for 20 minutes before being spun down at $4^{\circ} \mathrm{C}$, and the lipocalin-2 concentration of the supernatant was measured.

Histologic analysis. Enteritis and colitis scoring was performed by a blinded trained pathologist based on the scoring criteria in ref. 84. 
Immunofluorescence analysis of Tregs in LNs. LNs were fixed overnight in 4\% periodate-lysine-paraformaldehyde solution at $4^{\circ} \mathrm{C}$; serially passed through $10 \%, 20 \%$, and $30 \%$ sucrose solutions for 24 hours each; embedded in OCT compound; and rapidly frozen in ethanol cooled on dry ice. Thawed $20-\mu \mathrm{m}$ cryotome sections adhered onto superfrost glass slides were washed 3 times for 5 minutes each with PBS without $\mathrm{Ca}^{2+} / \mathrm{Mg}^{2+}$, permeabilized with precooled $90 \%$ methanol for 10 minutes at $-20^{\circ} \mathrm{C}$, washed for 30 minutes, treated with the Endogenous Biotin-Blocking Kit (Thermo Fisher), and blocked in FC block (1:200, Biolegend) with 1\% goat serum and $0.25 \%$ BSA in PBS for 1 hour. Sections were then incubated overnight at $4^{\circ} \mathrm{C}$ with biotinylated anti-FOXP3 antibody (1:50, clone FJK-16s, Affymetrix) in blocking solution and, after thorough washing, stained with Streptavidin-Alexa Fluor 647 (1:500, Thermo Fisher) for 8 hours at $4^{\circ} \mathrm{C}$, washed, and stained with Pacific Blue-conjugated anti-B220 antibody (1:200, Biolegend) for 8 hours at $4^{\circ} \mathrm{C}$. After several thorough washings, sections were mounted on coverslips in Prolong Gold (Thermo Fisher). In order to visualize entire LN sections, tile imaging was performed on a LSM 780 AxioObserver confocal microscope (Carl Zeiss) equipped with a $\times 40$ lens (Apochromat, $1.1 \mathrm{~W}$ Korr M27). Pacific blue was excited by $405-\mathrm{nm}$ laser line, and emission was collected with MBS 405 (424-509 nm). Alexa Fluor 647 was excited by 633-nm laser line, and emission was collected with MBS488/568/633 (638-755 nm). Images were processed in FIJI (open-source).

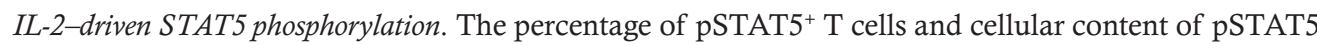
was determined before and after stimulation for 15 minutes with concentrations of mouse IL-2 (R\&D Systems) as indicated in the figure legends. Cells were fixed using BD Cytofix fixation buffer and permeabilized with BD Phosflow Perm buffer III. After permeabilization, cells were stained with anti-STAT5 pY694 (clone 47, BD Biosciences) and anti-STAT5 (44-386G, ThermoFisher).

Immunoprecipitation and immunoblotting assays. Cells were lysed in $0.5 \% \mathrm{NP}-40$ buffer $(150 \mathrm{mM} \mathrm{NaCl}$, $25 \mathrm{mM}$ Tris- $\mathrm{Cl}$ [pH 7.5], $5 \mathrm{mM}$ EDTA) containing complete protease inhibitors (Roche). Cell lysates were incubated with anti-DOCK8 (rabbit polyclonal, Sigma-Aldrich) or anti-STAT5 (C-17, Santa Cruz). Immune complexes were captured with protein G-Sepharose (EMD Millipore), washed, denatured by boiling in sample buffer, separated on acrylamide gels, and analyzed by immunoblotting with antiDOCK8 (H-159, Santa Cruz) and anti-STAT5 (C-17, Santa Cruz). Protein band intensities were quantified by densitometry using the ImageJ software (NIH).

Determination of cellular F-actin content. Splenocytes were rested in RPMI-1640 for 3 hours on ice. Cells were then incubated with $10 \mu \mathrm{g} / \mathrm{ml}$ rat anti-mouse CD3 mAb KT3 (Serotec) for 20 minutes on ice and stimulated by cross-linking with $20 \mu \mathrm{g} / \mathrm{ml} \mathrm{F}\left(\mathrm{ab}^{\prime}\right)_{2}$ goat anti-rat IgG secondary antibody (Jackson Immunoresearch Laboratories Inc.) for the indicated times at $37^{\circ} \mathrm{C}$. Cells were fixed in $4 \%$ formaldehyde, washed, and permeabilized with the BD Cytofix/Cytoperm kit (BD Biosciences). F-actin was stained with fluorescein isothiocyanate-labeled phalloidin (Sigma-Aldrich), and F-actin content was measured with a BD LSRFortessa cell analyzer.

IS visualization. $\mathrm{CD} 4{ }^{+} \mathrm{CD} 25^{+} \mathrm{T}$ cells freshly isolated from $D o c k 8^{-1-}$ and WT mice were incubated in glass chambers (Mat-tek) precoated with $10 \mu \mathrm{g} / \mathrm{ml}$ anti-CD3 (2C11, Affymetrix) and $1 \mu \mathrm{g} / \mathrm{ml}$ ICAM-1 (extracellular fragment) (85), for 5,10 , or 45 minutes at $37^{\circ} \mathrm{C}(53)$. Cells were then fixed using PHEM buffer at $37^{\circ} \mathrm{C}$, permeabilized (0.1\% Triton-X 100, 5 minutes), and stained with Alexa 568-phalloidin (Life Technologies), anti-p130CASL (pY165), anti-phosphotyrosine (multi-mAb rabbit antibody), anti-pZAP70 (pTyr319)/ pSyk(Tyr352) (Cell Signaling Technologies), and anti-TALIN (C20, goat polyclonal) (Santa Cruz Biotechnology) antibodies overnight, followed by incubation with fluorescently labeled anti-rabbit or anti-goat secondary antibodies for 1 hour. Cells were then imaged using TIRF microscopy using a Nikon Eclipse Ti microscope equipped with a $\times 1001.49$ NA TIRF objective, and an AndorDU897 back illuminated EMC$\mathrm{CD}$ camera. The acquired images were analyzed using ImageJ software as described previously (53). The cell boundaries were identified using the "particle analysis" plug-in of ImageJ, and the ROI obtained were further utilized extract morphological and intensity information associated with the raw images.

Transendocytosis. CHO-K1 cells (ATCC) were transfected with a vector encoding CD86-GFP (Origene), and stable transfectants were selected for with G418 (Sigma-Aldrich). CD86-GFP expressing CHO cells were then cocultured with sorted $\mathrm{CD} 4^{+} \mathrm{CD} 25^{+} \mathrm{CD} 39^{+}$Tregs at a 1:1 ratio in the presence of $10 \mathrm{nM}$ bafilomycin A (Invivogen). Uptake of GFP by Tregs was measured by FACS after 24 hours of coculture.

Quantitative analysis of gene expression and code availability. Tregs were isolated by fluorescent sorting for $\mathrm{CD} 4^{+} \mathrm{CD} 25^{+} \mathrm{CD} 39^{+}, \mathrm{CD}^{+} \mathrm{CD} 25^{+} \mathrm{CD} 39^{+} \mathrm{YFP}^{+}$, or $\mathrm{CD} 4^{+} \mathrm{CD} 25^{+} \mathrm{CD} 39^{+} \mathrm{YFP}^{-}$Tregs. RNA was isolated using a RNAeasy Plus micro kit (Qiagen) according to the manufacturer's instructions. Total small intestine and colonic RNA were isolated by homogenization in lysis/binding solution followed by RNA isolation using an RNAquesous phenol-free total RNA isolation kit (Ambion) according to the manufacturer's instructions. 
Complementary DNA was reverse transcribed using an iScript cDNA synthesis kit (Biorad) according to the manufacturer's instructions. Analysis of transcripts was performed with commercial TaqMan primer/probe sets against mouse b2m, Il2ra, Foxp3, Tgfb1, Capg, Tigit, Stat1, Il10, Il2, Ifng, Il17a, Il4, Il5, and Il13 (Thermo Fisher).

For RNAseq, $\mathrm{CD} 4{ }^{+} \mathrm{CD} 25^{+} \mathrm{CD} 39^{+} \mathrm{YFP}^{+}$and $\mathrm{CD} 4{ }^{+} \mathrm{CD} 25^{+} \mathrm{CD} 39^{+} \mathrm{YFP}^{-}$Tregs were isolated from the

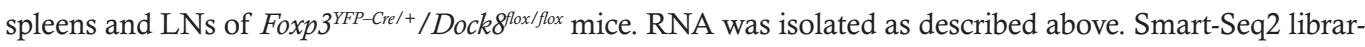
ies were generated and sequenced using a Broad Genomics Platform (86-88). The quality of the sequencing files was initially assessed with the FastQC tool. They were then trimmed to remove contaminant sequences (like polyA tails), adapters, and low-quality sequences with cutadapt. These trimmed reads were aligned to the mouse genome (UCSC build mm10) using STAR aligner. Alignments were checked using a combination of FastQC, Qualimap, MultiQC, and custom tools. Counts of reads aligning to known genes were generated by featureCounts. In parallel, transcripts per million measurements per isoform were generated using Sailfish. Differential expression at the gene level was called with DESeq2. We used the counts per gene estimated from Sailfish by tximport as input to DESeq2, as quantifying at the isoform level has been shown to produce more accurate results at the gene level. The GEO accession is GSE102577.

Statistics. Comparisons were analyzed for statistical significance using unpaired 2-tailed Student's $t$ test and 2-way ANOVA to determine $P$ values using GraphPad Software. A $P$ value of less than 0.05 was considered significant.

Study approval. All mouse studies were approved and performed in accordance with Boston Children's Hospital Institutional Animal Research and Care Committee.

\section{Author contributions}

EJ, SK, MT, SU, JMJT, MCR, RTB, VB, and SMU performed the experiments and analyzed the data. EJ generated the mutated mice. TRM, DJI, and RSG designed and supervised the research. EJ, SK, and RSG wrote the manuscript.

\section{Acknowledgments}

This study was supported by the United States Public Health Service (RO1AI114588 to RSG) and NIH grants (K08AI114968 to EJ and P01 AI078897 to TRM). The authors thank T. Chatila, H. Oettgen, and L.M. Charbonnier for useful discussion and advice.

Address correspondence to: Raif S. Geha, Boston Children's Hospital, Division of Immunology, One Blackfan Circle, Boston, Massachusetts 02115, USA. Phone: 617.919.2482; Email: raif.geha@childrens.harvard.edu.

1. Goldrath AW, Bevan MJ. Selecting and maintaining a diverse T-cell repertoire. Nature. 1999;402(6759):255-262

2. Laufer TM, Fan L, Glimcher LH. Self-reactive T cells selected on thymic cortical epithelium are polyclonal and are pathogenic in vivo. J Immunol. 1999;162(9):5078-5084.

3. Sakaguchi S, Yamaguchi T, Nomura T, Ono M. Regulatory T cells and immune tolerance. Cell. 2008;133(5):775-787.

4. Waisman A, Lukas D, Clausen BE, Yogev N. Dendritic cells as gatekeepers of tolerance. Semin Immunopathol. 2017;39(2):153-163.

5. Mahmud SA, et al. Costimulation via the tumor-necrosis factor receptor superfamily couples TCR signal strength to the thymic differentiation of regulatory T cells. Nat Immunol. 2014;15(5):473-481.

6. Perry JS, Hsieh CS. Development of T-cell tolerance utilizes both cell-autonomous and cooperative presentation of self-antigen Immunol Rev. 2016;271(1):141-155.

7. Malek TR, Castro I. Interleukin-2 receptor signaling: at the interface between tolerance and immunity. Immunity. 2010;33(2):153-165.

8. Pandiyan P, Lenardo MJ. The control of $\mathrm{CD}^{+} \mathrm{CD}_{25}{ }^{+} \mathrm{Foxp}^{+}$regulatory T cell survival. Biol Direct. 2008;3:6.

9. Yao Z, et al. Nonredundant roles for Stat5a/b in directly regulating Foxp3. Blood. 2007;109(10):4368-4375.

10. Li MO, Rudensky AY. T cell receptor signalling in the control of regulatory T cell differentiation and function. Nat Rev Immunol 2016;16(4):220-233.

11. Bacchetta R, Barzaghi F, Roncarolo MG. From IPEX syndrome to FOXP3 mutation: a lesson on immune dysregulation [published online ahead of print February 25, 2016]. Ann N Y Acad Sci. doi: 10.1111/nyas.13011.

12. Meller N, Merlot S, Guda C. CZH proteins: a new family of Rho-GEFs. J Cell Sci. 2005;118(pt 21):4937-4946.

13. Côté JF, Vuori K. GEF what? Dock180 and related proteins help Rac to polarize cells in new ways. Trends Cell Biol. 2007;17(8):383-393

14. Harada Y, et al. DOCK8 is a Cdc42 activator critical for interstitial dendritic cell migration during immune responses. Blood. 2012;119(19):4451-4461.

15. Randall KL, et al. Dock8 mutations cripple B cell immunological synapses, germinal centers and long-lived antibody production. Nat Immunol. 2009;10(12):1283-1291

16. Janssen E, et al. A DOCK8-WIP-WASp complex links T cell receptors to the actin cytoskeleton. J Clin Invest. 
2016;126(10):3837-3851.

17. Mizesko MC, et al. Defective actin accumulation impairs human natural killer cell function in patients with dedicator of cytokinesis 8 deficiency. J Allergy Clin Immunol. 2013;131(3):840-848.

18. Randall KL, et al. DOCK8 deficiency impairs CD8 T cell survival and function in humans and mice. J Exp Med. 2011;208(11):2305-2320.

19. Engelhardt KR, et al. The extended clinical phenotype of 64 patients with dedicator of cytokinesis 8 deficiency. J Allergy Clin Immunol. 2015;136(2):402-412.

20. Engelhardt KR, et al. Large deletions and point mutations involving the dedicator of cytokinesis 8 (DOCK8) in the autosomal-recessive form of hyper-IgE syndrome. J Allergy Clin Immunol. 2009;124(6):1289-302.e4.

21. Zhang Q, et al. Combined immunodeficiency associated with DOCK8 mutations. N Engl J Med. 2009;361(21):2046-2055.

22. Janssen E, et al. Dedicator of cytokinesis 8-deficient patients have a breakdown in peripheral B-cell tolerance and defective regulatory T cells. J Allergy Clin Immunol. 2014;134(6):1365-1374.

23. Al-Herz W, et al. Clinical, immunologic and genetic profiles of DOCK8-deficient patients in Kuwait. Clin Immunol. 2012;143(3):266-272.

24. Alsum Z, et al. Clinical, immunological and molecular characterization of DOCK8 and DOCK8-like deficient patients: single center experience of twenty-five patients. J Clin Immunol. 2013;33(1):55-67.

25. Sanal O, et al. Additional diverse findings expand the clinical presentation of DOCK 8 deficiency. J Clin Immunol. 2012;32(4):698-708

26. Su HC. Dedicator of cytokinesis 8 (DOCK8) deficiency. Curr Opin Allergy Clin Immunol. 2010;10(6):515-520.

27. Engelhardt KR, et al. The extended clinical phenotype of 64 patients with dedicator of cytokinesis 8 deficiency. $J$ Allergy Clin Immunol. 2015;136(2):402-412.

28. Lambe T, et al. DOCK8 is essential for T-cell survival and the maintenance of CD8 $8^{+}$T-cell memory. Eur J Immunol. 2011;41(12):3423-3435.

29. Miyara M, et al. Functional delineation and differentiation dynamics of human $\mathrm{CD}^{+} \mathrm{T}$ cells expressing the FoxP3 transcription factor. Immunity. 2009;30(6):899-911.

30. Kwon HS, Lim HW, Wu J, Schnölzer M, Verdin E, Ott M. Three novel acetylation sites in the Foxp3 transcription factor regulate the suppressive activity of regulatory T cells. J Immunol. 2012;188(6):2712-2721.

31. Perl K, et al. Reduced changes in protein compared to mRNA levels across non-proliferating tissues. BMC Genomics. 2017;18(1):305

32. Greenbaum D, Colangelo C, Williams K, Gerstein M. Comparing protein abundance and mRNA expression levels on a genomic scale. Genome Biol. 2003;4(9):117.

33. de Sousa Abreu R, Penalva LO, Marcotte EM, Vogel C. Global signatures of protein and mRNA expression levels. Mol Biosyst. 2009;5(12):1512-1526

34. Thornton AM, Donovan EE, Piccirillo CA, Shevach EM. Cutting edge: IL-2 is critically required for the in vitro activation of $\mathrm{CD}^{+}{ }^{+} \mathrm{CD} 25^{+} \mathrm{T}$ cell suppressor function. J Immunol. 2004;172(11):6519-6523.

35. Jonuleit H, Schmitt E, Kakirman H, Stassen M, Knop J, Enk AH. Infectious tolerance: human CD25(+) regulatory T cells convey suppressor activity to conventional CD4(+) T helper cells. J Exp Med. 2002;196(2):255-260.

36. Palomares $\mathrm{O}$, et al. Regulatory $\mathrm{T}$ cells and immune regulation of allergic diseases: roles of IL-10 and TGF- $\beta$. Genes Immun. 2014;15(8):511-520.

37. Li QZ, et al. Protein array autoantibody profiles for insights into systemic lupus erythematosus and incomplete lupus syndromes. Clin Exp Immunol. 2007;147(1):60-70.

38. Le PT, Muller MT, Mortensen RF. Acute phase reactants of mice. I. Isolation of serum amyloid P-component (SAP) and its induction by a monokine. J Immunol. 1982;129(2):665-672.

39. Tong P, Wesemann DR. Molecular mechanisms of IgE class switch recombination. Curr Top Microbiol Immunol. 2015;388:21-37.

40. Yamada A, Arakaki R, Saito M, Tsunematsu T, Kudo Y, Ishimaru N. Role of regulatory T cell in the pathogenesis of inflammatory bowel disease. World J Gastroenterol. 2016;22(7):2195-2205.

41. Jones CM, Callaghan JM, Gleeson PA, Mori Y, Masuda T, Toh BH. The parietal cell autoantigens recognized in neonatal thymectomy-induced murine gastritis are the alpha and beta subunits of the gastric proton pump [corrected]. Gastroenterology. 1991;101(2):287-294.

42. Tung KS, et al. Murine autoimmune oophoritis, epididymoorchitis, and gastritis induced by day 3 thymectomy. Autoantibodies. Am J Pathol. 1987;126(2):303-314.

43. Chassaing B, Srinivasan G, Delgado MA, Young AN, Gewirtz AT, Vijay-Kumar M. Fecal lipocalin 2, a sensitive and broadly dynamic non-invasive biomarker for intestinal inflammation. PLoS One. 2012;7(9):e44328.

44. Zhang Z, Zhang W, Guo J, Gu Q, Zhu X, Zhou X. Activation and functional specialization of regulatory T cells lead to the generation of Foxp3 instability. J Immunol. 2017;198(7):2612-2625.

45. Liu Z, Gerner MY, Van Panhuys N, Levine AG, Rudensky AY, Germain RN. Immune homeostasis enforced by co-localized effector and regulatory T cells. Nature. 2015;528(7581):225-230.

46. Zhang Q, et al. DOCK8 regulates lymphocyte shape integrity for skin antiviral immunity. J Exp Med. 2014;211(13):2549-2566

47. Levine AG, Arvey A, Jin W, Rudensky AY. Continuous requirement for the TCR in regulatory T cell function. Nat Immunol. 2014;15(11):1070-1078.

48. Huang Y, Burkhardt JK. T-cell-receptor-dependent actin regulatory mechanisms. J Cell Sci. 2007;120(pt 5):723-730.

49. Qureshi OS, et al. Trans-endocytosis of CD80 and CD86: a molecular basis for the cell-extrinsic function of CTLA-4. Science. 2011;332(6029):600-603.

50. Hou TZ, et al. A transendocytosis model of CTLA-4 function predicts its suppressive behavior on regulatory T cells. $J$ Immunol. 2015;194(5):2148-2159

51. Thauland TJ, Koguchi Y, Dustin ML, Parker DC. CD28-CD80 interactions control regulatory T cell motility and immunological synapse formation. J Immunol. 2014;193(12):5894-5903.

52. Dustin ML. T-cell activation through immunological synapses and kinapses. Immunol Rev. 2008;221:77-89. 
53. Kumari S, et al. Actin foci facilitate activation of the phospholipase C- $\gamma$ in primary T lymphocytes via the WASP pathway. Elife. 2015;4.

54. Sawada Y, et al. Force sensing by mechanical extension of the Src family kinase substrate p130Cas. Cell. 2006;127(5):1015-1026.

55. Dustin ML, Bromley SK, Kan Z, Peterson DA, Unanue ER. Antigen receptor engagement delivers a stop signal to migrating T lymphocytes. Proc Natl Acad Sci U S A. 1997;94(8):3909-3913.

56. Domadia PN, Li YF, Bhunia A, Mohanram H, Tan SM, Bhattacharjya S. Functional and structural characterization of the talin F0F1 domain. Biochem Biophys Res Commun. 2010;391(1):159-165.

57. Ham H, et al. Dedicator of cytokinesis 8 interacts with talin and Wiskott-Aldrich syndrome protein to regulate NK cell cytotoxicity. J Immunol. 2013;190(7):3661-3669.

58. Nag S, Larsson M, Robinson RC, Burtnick LD. Gelsolin: the tail of a molecular gymnast. Cytoskeleton (Hoboken). 2013;70(7):360-384.

59. Smith MA, et al. LIM domains target actin regulators paxillin and zyxin to sites of stress fiber strain. PLoS One. 2013;8(8):e69378.

60. Kim J, et al. Coactosin-like 1 antagonizes cofilin to promote lamellipodial protrusion at the immune synapse. PLoS One. 2014;9(1):e85090.

61. Miyazaki M, et al. Id2 and Id3 maintain the regulatory T cell pool to suppress inflammatory disease. Nat Immunol. 2014;15(8):767-776.

62. Duhen T, Duhen R, Lanzavecchia A, Sallusto F, Campbell DJ. Functionally distinct subsets of human FOXP ${ }^{+}$Treg cells that phenotypically mirror effector Th cells. Blood. 2012;119(19):4430-4440.

63. Yu F, Sharma S, Edwards J, Feigenbaum L, Zhu J. Dynamic expression of transcription factors T-bet and GATA-3 by regulatory T cells maintains immunotolerance. Nat Immunol. 2015;16(2):197-206.

64. Zhao W, Dong Y, Wu C, Ma Y, Jin Y, Ji Y. TIGIT overexpression diminishes the function of CD4 T cells and ameliorates the severity of rheumatoid arthritis in mouse models. Exp Cell Res. 2016;340(1):132-138.

65. Kurtulus S, et al. TIGIT predominantly regulates the immune response via regulatory T cells. J Clin Invest. 2015;125(11):4053-4062.

66. Grinberg-Bleyer Y, et al. IL-2 reverses established type 1 diabetes in NOD mice by a local effect on pancreatic regulatory T cells J Exp Med. 2010;207(9):1871-1878.

67. Takahashi R, et al. SOCS1 is essential for regulatory T cell functions by preventing loss of Foxp3 expression as well as IFN- $\gamma$ and IL-17A production. J Exp Med. 2011;208(10):2055-2067.

68. Van Belle TL, et al. 1,25-Dihydroxyvitamin D3 and its analog TX527 promote a stable regulatory T cell phenotype in T cells from type 1 diabetes patients. PLoS One. 2014;9(10):e109194.

69. Delgoffe GM, et al. Stability and function of regulatory T cells is maintained by a neuropilin-1-semaphorin-4a axis. Nature. 2013;501(7466):252-256.

70. Agenès F, Bosco N, Mascarell L, Fritah S, Ceredig R. Differential expression of regulator of G-protein signalling transcripts and in vivo migration of $\mathrm{CD}^{+}$naïve and regulatory T cells. Immunology. 2005;115(2):179-188.

71. Francisco LM, Sage PT, Sharpe AH. The PD-1 pathway in tolerance and autoimmunity. Immunol Rev. 2010;236:219-242.

72. Al-Banna NA, Vaci M, Slauenwhite D, Johnston B, Issekutz TB. CCR4 and CXCR3 play different roles in the migration of T cells to inflammation in skin, arthritic joints, and lymph nodes. Eur J Immunol. 2014;44(6):1633-1643.

73. Downs-Canner S, et al. Suppressive IL-17A(+)Foxp3(+) and ex-Th17 IL-17A(neg)Foxp3(+) Treg cells are a source of tumour-associated Treg cells. Nat Commun. 2017;8:14649.

74. Braun A, et al. Integrin $\alpha \mathrm{E}(\mathrm{CD} 103)$ is involved in regulatory T-cell function in allergic contact hypersensitivity. J Invest Dermatol. 2015;135(12):2982-2991.

75. Wang C, et al. BATF is required for normal expression of gut-homing receptors by $\mathrm{T}$ helper cells in response to retinoic acid. JExp Med. 2013;210(3):475-489.

76. Nielsen $\mathrm{OH}$, et al. Rectal dialysate and fecal concentrations of neutrophil gelatinase-associated lipocalin, interleukin-8, and tumor necrosis factor- $\alpha$ in ulcerative colitis. Am J Gastroenterol. 1999;94(10):2923-2928.

77. Ward MA, et al. Insights into the pathogenesis of ulcerative colitis from a murine model of stasis-induced dysbiosis, colonic metaplasia, and genetic susceptibility. Am J Physiol Gastrointest Liver Physiol. 2016;310(11):G973-G988.

78. Ohnmacht C, et al. MUCOSAL IMMUNOLOGY. The microbiota regulates type 2 immunity through RORgammat(+) T cells. Science. 2015;349(6251):989-993.

79. Eun CS, et al. Induction of bacterial antigen-specific colitis by a simplified human microbiota consortium in gnotobiotic interleukin-10-/- mice. Infect Immun. 2014;82(6):2239-2246.

80. Sanal O, et al. Additional diverse findings expand the clinical presentation of DOCK8 deficiency. J Clin Immunol. 2012;32(4):698-708.

81. Santos LC, et al. Actin polymerization-dependent activation of Cas-L promotes immunological synapse stability. Immunol Cell Biol. 2016;94(10):981-993.

82. Faustino L, et al. Regulatory T cells migrate to airways via CCR4 and attenuate the severity of airway allergic inflammation. J Immunol. 2013;190(6):2614-2621.

83. Joller N, et al. Treg cells expressing the coinhibitory molecule TIGIT selectively inhibit proinflammatory Th1 and Th17 cell responses. Immunity. 2014;40(4):569-581.

84. Erben U, et al. A guide to histomorphological evaluation of intestinal inflammation in mouse models. Int J Clin Exp Pathol. 2014;7(8):4557-4576.

85. Kumari S, et al. T lymphocyte myosin IIA is required for maturation of the immunological synapse. Front Immunol. 2012;3:230.

86. Picelli S, Björklund ÅK, Faridani OR, Sagasser S, Winberg G, Sandberg R. Smart-seq2 for sensitive full-length transcriptome profiling in single cells. Nat Methods. 2013;10(11):1096-1098.

87. Picelli S, Faridani OR, Björklund AK, Winberg G, Sagasser S, Sandberg R. Full-length RNA-seq from single cells using Smartseq2. Nat Protoc. 2014;9(1):171-181.

88. Trombetta JJ, Gennert D, Lu D, Satija R, Shalek AK, Regev A. Preparation of single-cell RNA-seq libraries for next generation sequencing. Curr Protoc Mol Biol. 2014;107:4.22.1-4.2217. 